\title{
Dramatic Weakening of the Tropical Easterly Jet Projected by CMIP6 Models
}

\author{
SIHUA HUANG \\ Center for Monsoon and Environment Research and School of Atmospheric Sciences, Sun Yat-sen University, \\ Guangzhou, China \\ BIN WANG \\ Department of Atmospheric Sciences and International Pacific Research Center, University of Hawai' $i$ at Mānoa, Honolulu, \\ Hawaii, and Earth System Modeling Center, Nanjing University of Information Science and Technology, Nanjing, China

\section{ZHIPING WEN} \\ Department of Atmospheric and Oceanic Sciences and Institute of Atmospheric Sciences, Fudan University, Shanghai, and \\ Jiangsu Collaborative Innovation Center for Climate Change, Nanjing, China
}

(Manuscript received 29 December 2019, in final form 18 May 2020)

\begin{abstract}
The upper-level tropical easterly jet (TEJ) is a crucial component of the summer monsoon system and tropical general circulation. The simulation and projection of the TEJ, however, have not been assessed. Here we evaluate models' fidelity and assess the future change of the TEJ by utilizing 16 models that participated in phase 6 of the Coupled Model Intercomparison Project (CMIP6). Most of the models can reproduce the TEJ reasonably well in terms of climatology, seasonal evolution, and interannual variability. Nevertheless, underestimation of the TEJ's intensity and extent is identified, with the maximum bias occurring in the jet centers over the tropical Indian Ocean (IO) and the tropical eastern Pacific (EP). Under the shared socioeconomic pathway $5-8.5$, the multimodel ensemble projects a remarkable reduction in the central TEJ intensity by about $18 \%$ over the IO and $77 \%$ over the EP toward the end of the twenty-first century. The mean intensity of TEJ will weaken by about $11 \%$, and the extent will reduce by $6 \%$, suggesting a significantly weakened upper-level monsoon circulation in the future climate. The projected El Niño-like warming pattern over the tropical Pacific may play a critical role in the future weakening of the TEJ via inducing suppressed rainfall over the tropical eastern IO and Central America. The model uncertainties in the projected TEJ changes may arise from the uncertainties in the models' projected tropical EP warming. The sensitivity of future projections to model selection is also examined. Results show that the selection of models based on different physical considerations does not yield a significantly different projection.
\end{abstract}

\section{Introduction}

The tropical easterly jet (TEJ) is a prominent feature of the upper-level circulation in tropics as well as an essential component of monsoon system, which exerts great impacts on weather and climate over monsoon regions and even global tropics (e.g., Krishnamurti and Bhalme 1976; Koteswaram 1958; Hulme and Tosdevin 1989; Sathiyamoorthy et al. 2004; Rao et al. 2004). In boreal summer, two jet centers are observed at $200 \mathrm{hPa}$ (Figs. 1a-c). The stronger one is located over the Indian Ocean (IO) with a maximum wind speed reaching $23 \mathrm{~m} \mathrm{~s}^{-1}$,

Corresponding author: Bin Wang, wangbin@hawaii.edu which results from the meridional thermal contrast between the Asian landmass and the IO and is enhanced by the elevated heating over the Tibetan Plateau (Koteswaram 1958). The intensity of the TEJ located over the tropical eastern Pacific (EP) is only one-third of the intensity of the IO TEJ, but it is a crucial component of the North America summer monsoon system. Here we will investigate both of the IO and EP TEJs, trying to unravel more concrete characteristics by comparing them.

The IO TEJ develops and retreats during the onset and withdrawal of the Asian summer monsoon, respectively, exhibiting a significant seasonal migration (Ding et al. 1988). As for the EP TEJ, it forms when the mid- to 


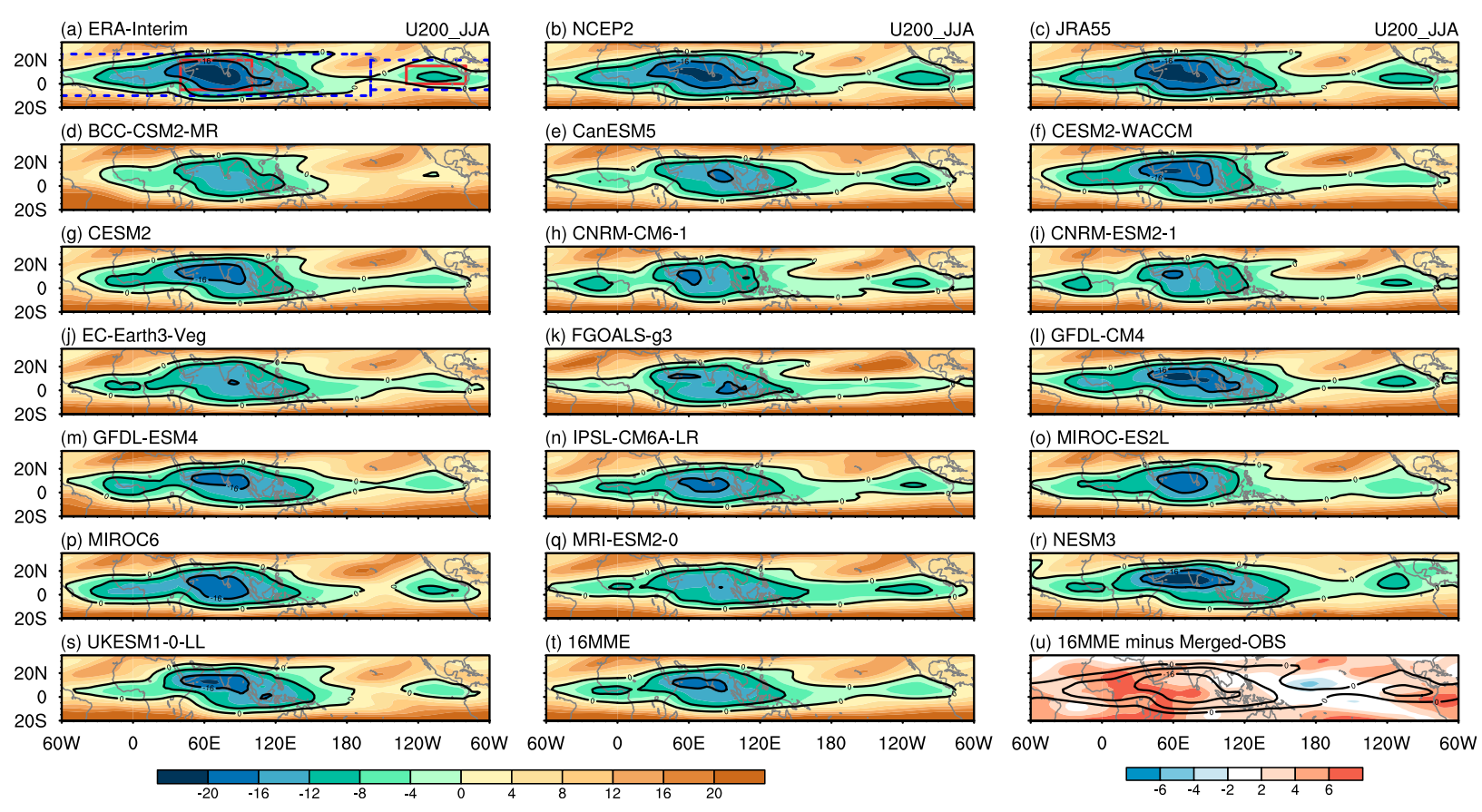

FIG. 1. Climatological zonal wind at $200 \mathrm{hPa}$ (shading; $\mathrm{m} \mathrm{s}^{-1}$ ) in boreal summer (June-August) from 1995 to 2014 derived from (a)-(c) observations, (d)-(s) 16 individual model simulations, (t) the ensemble mean of the 16 models (16MME), and (u) 16MME bias. The contour interval is $8 \mathrm{~m} \mathrm{~s}^{-1}$, and only easterlies are plotted. The contour in $(\mathrm{u})$ indicates the easterly wind derived from the merged data of ERA-Interim, NCEP-2, and JRA-55. The model bias is calculated as the difference between the 16MME and the merged observation. The red boxes in (a) denote the region of the IO $\left(5^{\circ} \mathrm{S}-20^{\circ} \mathrm{N}, 40^{\circ}-100^{\circ} \mathrm{E}\right)$ and the $\mathrm{EP}\left(0^{\circ}-15^{\circ} \mathrm{N}, 130^{\circ}-80^{\circ} \mathrm{W}\right)$, respectively, while the blue boxes denote the western jet $\left(10^{\circ} \mathrm{S}-25^{\circ} \mathrm{N}, 60^{\circ}-160^{\circ} \mathrm{W}\right)$ and the eastern jet $\left(5^{\circ} \mathrm{S}-20^{\circ} \mathrm{N}, 160^{\circ}-60^{\circ} \mathrm{W}\right)$, respectively.

upper-level flow shifts from westerly to easterly, associated with the Mexican high dominating the uppertropospheric circulation in boreal summer (Barlow et al. 1998; Douglas et al. 1993; Higgins et al. 1997; Murakami et al. 1992). On the interannual time scale, the TEJ is tightly associated with the monsoon rainfall and primarily attributed to the tropical sea surface temperature (SST) anomalies over the tropical central-eastern Pacific. The Indian summer monsoon rainfall enhances during a stronger TEJ and decreases during a weaker TEJ (Pattanaik and Satyan 2000; Kanamitsu et al. 1972; Tanaka 1982). Meanwhile, the TEJ can be strengthened by a La Niña event and weakened by an El Niño event (Arkin 1982; Tanaka 1982; Chen and van Loon 1987; Huang et al. 2019). Since model simulations have been conducted in the past to evaluate the representation of the lower-level monsoon system (e.g., Song and Zhou 2014; Sperber et al. 2013; Ogata et al. 2014; He and Zhou 2014; Kusunoki and Arakawa 2015), the model fidelity in representing the TEJ and its variability remains largely unknown.

Many studies have focused on the response of monsoon system to global warming by utilizing the future projections in the Coupled Model Intercomparison Project (CMIP) models, especially within the monsoon regions (e.g., Maloney et al. 2014; Seo et al. 2013; Kusunoki and Arakawa 2012; Sooraj et al. 2016; Lee and Wang 2014). It is well known that although the total precipitation over the Asian monsoon region tends to increase significantly, the low-level tropical circulation will weaken under global warming due to the increased static stability (Wang et al. 2014) and reduced meridional thermal gradient (Ueda et al. 2006). In addition, the intensity of the atmospheric overturning circulation, such as the Walker circulation, decreases as the climate warms (Held and Soden 2006; Vecchi and Soden 2007; Haarsma and Selten 2012). Although it is a prominent feature of the monsoon system and tropical general circulation, how and to what extent the TEJ will change in its intensity, extent, and location under global warming are not yet fully understood.

Considering the scientific gaps identified in phase 5 of CMIP (CMIP5) reported in Stouffer et al. (2017), using phase 6 of CMIP (CMIP6), building on the previous phases of CMIP, is recommended. Compared to CMIP5 in which modeling groups worked independently, CMIP6 tends to address the specific questions related to the response of the Earth system to forcing, origins, and consequences of systematic bias, and assessment of the future climate changes (Eyring et al. 2016). CMIP6 also 
TABLE 1. The 16 CMIP6 models involved in this study and their development institutes and horizontal resolution.

\begin{tabular}{|c|c|c|c|}
\hline No. & Model name & Horizontal resolution (longitude $\times$ latitude) & Institute \\
\hline 1 & BCC-CSM2-MR & $1.125^{\circ} \times 1.125^{\circ}$ & Beijing Climate Center, China \\
\hline 2 & CanESM5 & $2.8125^{\circ} \times 2.8125^{\circ}$ & $\begin{array}{l}\text { Canadian Centre for Climate Modeling } \\
\text { and Analysis, Canada }\end{array}$ \\
\hline 3 & CESM2-WACCM & $1.25^{\circ} \times 0.9375^{\circ}$ & National Center for Atmospheric \\
\hline 4 & CESM2 & $1.25^{\circ} \times 0.9375^{\circ}$ & Research, United States \\
\hline 5 & CNRM-CM6.1 & $1.4^{\circ} \times 1.4^{\circ}$ & Centre National de Recherches \\
\hline 6 & CNRM-ESM2.1 & $1.4^{\circ} \times 1.4^{\circ}$ & Météorologiques, France \\
\hline 7 & EC-Earth3-Veg & $0.7^{\circ} \times 0.7^{\circ}$ & European Center-Earth Consortium \\
\hline 8 & FGOALS-g3 & $2^{\circ} \times 2.25^{\circ}$ & Chinese Academy of Sciences, China \\
\hline 9 & GFDL-CM4 & $1.25^{\circ} \times 1^{\circ}$ & National Oceanic and Atmospheric \\
\hline 10 & GFDL-ESM4 & $1.25^{\circ} \times 1^{\circ}$ & $\begin{array}{l}\text { Administration and Geophysical Fluid } \\
\text { Dynamics Laboratory, United States }\end{array}$ \\
\hline 11 & IPSL-CM6A-LR & $2.5^{\circ} \times 1.26^{\circ}$ & Institute Pierre Simon Laplace, France \\
\hline 12 & MIROC-ES2L & $2.8125^{\circ} \times 2.8125^{\circ}$ & Japan Agency for Marine-Earth Science \\
\hline 13 & MIROC6 & $2.8125^{\circ} \times 2.8125^{\circ}$ & $\begin{array}{l}\text { and Technology, Atmosphere and } \\
\text { Ocean Research Institute, National } \\
\text { Institute for Environmental Studies and } \\
\text { RIKEN Center for Computational } \\
\text { Science, Japan }\end{array}$ \\
\hline 14 & MRI-ESM2.0 & $1.125^{\circ} \times 1.125^{\circ}$ & Meteorological Research Institute, Japan \\
\hline 15 & NESM3 & $1.875^{\circ} \times 1.875^{\circ}$ & $\begin{array}{l}\text { Nanjing University of Information } \\
\text { Science and Technology, China }\end{array}$ \\
\hline 16 & UKESM1.0-LL & $1.875^{\circ} \times 1.24^{\circ}$ & $\begin{array}{l}\text { Met Office Hadley Centre, United } \\
\text { Kingdom }\end{array}$ \\
\hline
\end{tabular}

makes model output available to scientific communities in a common standard, infrastructure, and documentation (Balaji et al. 2018). Besides, CMIP6 has made an effort to quantify the radiative forcings from the different specified external factors by establishing new future pathways, the shared socioeconomic pathways (SSPs; O’Neill et al. 2016; Riahi et al. 2017), developed from the representative concentration pathways (RCPs; van Vuuren et al. 2011) in CMIP5. Hence, our motivation is to provide a broad evaluation of the latest CMIP6 model output in representing the present-day TEJ and projecting the future change of the TEJ under the new CMIP6 scenario.

Section 2 introduces the CMIP6 models and reanalysis datasets used in the present study. Section 3 assesses the models' fidelity in simulating the present-day TEJ. Section 4 evaluates the projected TEJ changes in future climate. The sources of the uncertainties in future projections and the sensitivity of projections to different model selection are also examined in section 4 . A summary and a discussion are presented in section 5 .

\section{Data and methods}

\section{a. CMIP6 data}

The model output archived from the CMIP6 models is used in this study, accessible through the Earth System
Grid Federation (ESGF) centers (https://esgf-node. llnl.gov/search/cmip6/). Table 1 outlines the 16 early released models from 12 modeling centers involved in this study. The historical simulation is carried out for the period from 1850 to 2014 , which is generated by the historical forcings based on observations including concentrations of $\mathrm{CO}_{2}$ and other long-lived greenhouse gases, volcanoes, solar forcing, and natural and anthropogenic aerosols, and land use (Eyring et al. 2016). The SSP5-8.5 (SSP585) scenario is chosen to examine the potentially substantial changes in the future projection of the TEJ, which represents the high end of the range of future pathways and assumes a radiative forcing of $8.5 \mathrm{~W} \mathrm{~m}^{-2}$ in 2100 . The last 20 years of simulations in both the historical and SSP585 scenario runs (i.e., 19952014 and 2081-2100) will be evaluated in order to determine the climate change. Note that eight Earth system models (i.e., CanESM5, CESM2-WACCM, CESM2, CNRM-ESM2.1, GFDL-ESM4, MIROCES2L, MRI-ESM2.0, and UKESM1.0-LL) and two climate models (i.e., GFDL-CM4 and IPSL-CM6A-LR) include a representation of the carbon cycle between the atmosphere, ocean, and biosphere when performing the historical and SSP585 simulations, while the remaining six models do not include the carbon cycle. All model output data are interpolated onto a resolution of $2.5^{\circ} \times 2.5^{\circ}$. 


\section{b. Observational data}

The reanalysis datasets used in the present study include 1) monthly atmospheric components derived from the European Centre for Medium-Range Weather Forecasts (ECMWF) interim reanalysis (ERA-Interim) (Simmons et al. 2007), the National Centers for Environmental Prediction (NCEP)-Department of Energy (DOE) reanalysis 2 (NCEP-2; Kanamitsu et al. 2002), and the Japan Meteorological Agency (JMA) 55-year Reanalysis (JRA-55; Kobayashi et al. 2015); 2) monthly mean precipitation data derived from Global Precipitation Climatology Project (GPCP) version 2.3 (Adler et al. 2003); and 3) monthly SST data derived from Hadley Centre Sea Surface Temperature version 1.1 (HadISST1; Rayner et al. 2003). The period is from 1995 to 2014, consistent with that in CMIP6 model historical evaluation. Due to the high consistency of the reanalysis dataset in climatology, a simply averaged atmospheric data of ERA-Interim, NCEP-2 and JRA-55 will be used as the merged observation.

\section{c. Definition of the TEJ index}

For an objective assessment on the TEJ, several metrics are defined to describe the TEJ's intensity, extension, and location. Taking the overall intensity and coverage of the TEJ into account, the TEJ's mean intensity index $I_{\text {mean }}$ and extent index $I_{\text {extent }}$ are defined as the average speed and the total area (sum of the grid points), respectively, of the $200-\mathrm{hPa}$ easterly wind between $20^{\circ} \mathrm{S}$ and $30^{\circ} \mathrm{N}$. The intensity in the centers of the IO and EP TEJs is considered for a specific description of the central TEJ, which is defined as the averaged 200$\mathrm{hPa}$ zonal wind over the IO region $\left(5^{\circ} \mathrm{S}-20^{\circ} \mathrm{N}, 40^{\circ}-\right.$ $100^{\circ} \mathrm{E}$; large red box in Fig. 1a) and EP region $\left(0^{\circ}-15^{\circ} \mathrm{N}\right.$, $130^{\circ}-80^{\circ} \mathrm{W}$; small red box in Fig. 1a) and referred to as $I_{\mathrm{IO}}$ and $I_{\mathrm{EP}}$, respectively. Besides, a weighted longitude index $I_{\mathrm{lon}}$ and latitude index $I_{\mathrm{lat}}$ are calculated as followed:

$$
\begin{gathered}
I_{\mathrm{lon}}=\frac{\sum_{j=1}^{M} \sum_{i=1}^{N} U_{i, j} x_{i}}{\sum_{j=1}^{M} \sum_{i=1}^{N} U_{i, j}}, i=1,2, \ldots, N ; j=1,2, \ldots, M, \\
I_{\mathrm{lat}}=\frac{\sum_{i=1}^{N} \sum_{j=1}^{M} U_{i, j} y_{j}}{\sum_{j=1}^{M} \sum_{i=1}^{N} U_{i, j}}, i=1,2, \ldots, N ; j=1,2, \ldots, M,
\end{gathered}
$$

$$
U_{i, j}=\left\{\begin{array}{c}
U_{i, j},\left|U_{i, j}\right| \geq\left|U_{\max }-a\right| \\
0,\left|U_{i, j}\right|<\left|U_{\max }-a\right|
\end{array},\right.
$$

where $x_{i}, y_{j}$, and $U_{i, j}$ denote the longitude, latitude, and zonal wind speed at the grid point $(i, j)$ within the region of $5^{\circ} \mathrm{S}-15^{\circ} \mathrm{N}, 50^{\circ}-135^{\circ} \mathrm{E}$ for IO TEJ and $10^{\circ} \mathrm{S}-10^{\circ} \mathrm{N}, 140^{\circ}-$ $50^{\circ} \mathrm{W}$ for EP TEJ, respectively. Also, $N$ and $M$ are the total grids of longitude and latitude in the target region, respectively; $U_{\max }$ denotes the maximum wind speed with the region mentioned above. Here, a wind region of $2 \mathrm{~m} \mathrm{~s}^{-1}$ (i.e., $a=2 \mathrm{~m} \mathrm{~s}^{-1}$ ) is considered for the TEJ over IO and $a=1 \mathrm{~m} \mathrm{~s}^{-1}$ for the TEJ over EP. Such a weighted longitude and latitude index is used to identify the location of the jet center.

\section{Simulated present-day TEJ in CMIP6 models}

\section{a. Climatology of TEJ in boreal summer}

Figure 1 compares the climatology of the TEJ simulated by CMIP6 models with the observational data in boreal summer. In observations, upper-level easterly wind covers most of the tropical regions with two jet centers located over the IO and EP (Figs. 1a-c). Two branches of the jet are observed in the entrance region of the IO TEJ, with a northern branch over the South China Sea and northwestern Pacific and a southern branch over Maritime Continent and tropical western Pacific. In general, the majority of the CMIP6 models can reproduce the IO and EP TEJs, but substantial biases can be found among individual models (Figs. 1d-s). For example, BCC-CSM2-MR poorly produces the EP TEJ (Fig. 1d). The multimodel ensemble (MME) mean of the 16 models (16MME) suffers a significant underestimation within the majority region of the TEJ (Figs. 1t,u). The largest bias occurs in the central and western IO TEJ as well as central and southeastern EP TEJ with a magnitude exceeding $6 \mathrm{~m} \mathrm{~s}^{-1}$.

Figure 2 compares the vertical structure of the zonal wind averaged along $0^{\circ}-15^{\circ} \mathrm{N}$ from the middle troposphere to the lower stratosphere. The observed center of the IO TEJ is located between 200 and $100 \mathrm{hPa}$, whereas the center of the EP TEJ is located at a lower height, mainly between 300 and $150 \mathrm{hPa}$ (Figs. 2a-c). Most of the CMIP6 models simulate reasonably well in the jet center of IO TEJ but have biases in capturing the EP TEJ (Figs. 2d-s). BCC-CSM2-MR (Fig. 2d) and FGOALS-g3 (Fig. 2k) fail in producing the EP TEJ, exhibiting strong westerly at the upper troposphere. Consistent with the horizontal distribution, the 16MME underestimates the intensity of both of the IO and EP TEJs' centers (Fig. 2u). 
(a) ERA-Interim

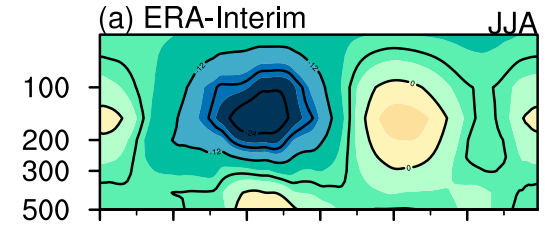

(d) BCC-CSM2-MR

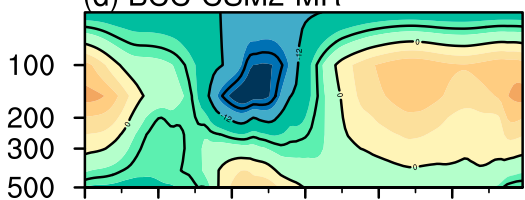

(g) CESM2
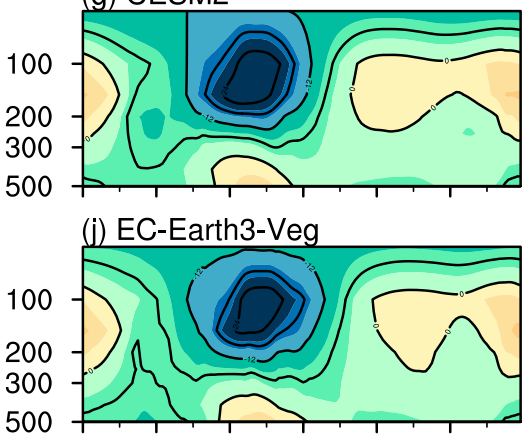

(m) GFDL-ESM4

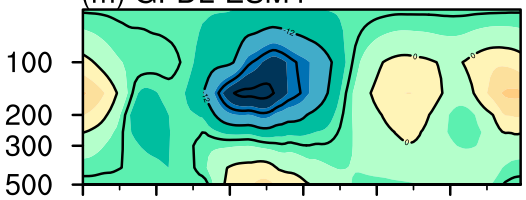

(p) MIROC6

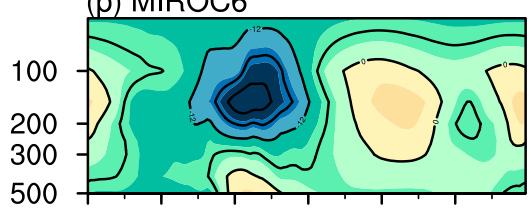

(s) UKESM1-0-LL

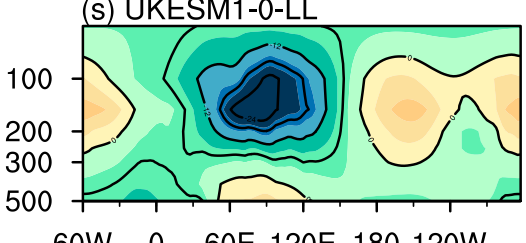

60W $0 \quad 60 \mathrm{E} 120 \mathrm{E} 180120 \mathrm{~W}$ (b) NCEP2

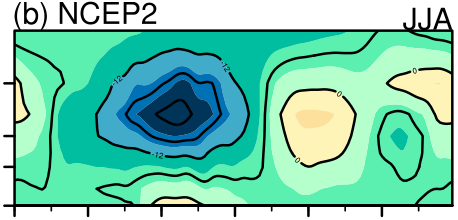

(e) CanESM5

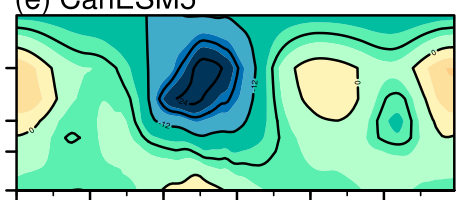

(h) CNRM-CM6-1

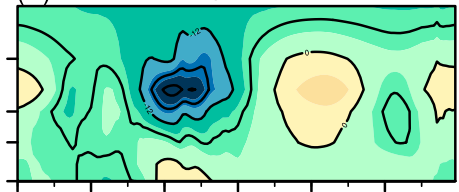

(k) FGOALS-g3

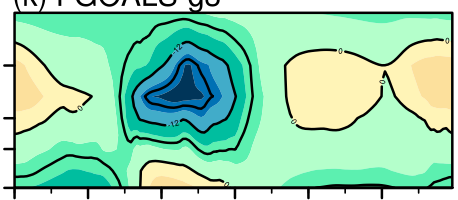

(n) IPSL-CM6A-LR

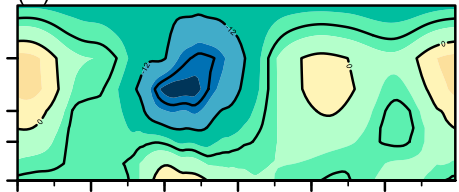

(q) MRI-ESM2-0

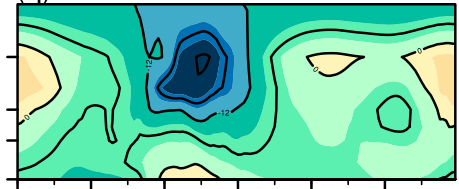

(t) $16 \mathrm{MME}$

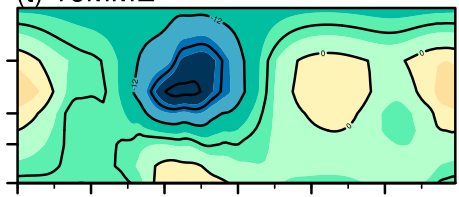

60W 0 60E 120E $180120 \mathrm{~W}$

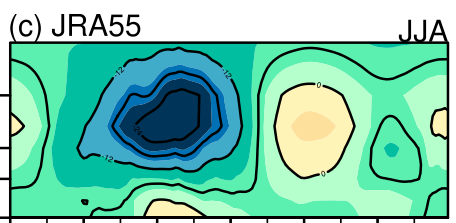

(f) CESM2-WACCM

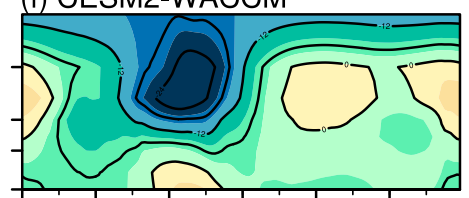

(i) CNRM-ESM2-1

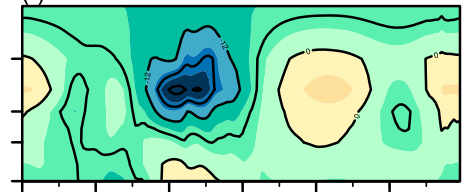

(I) GFDL-CM4

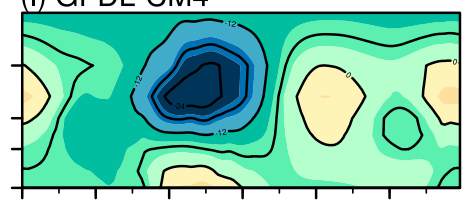

(o) MIROC-ES2L

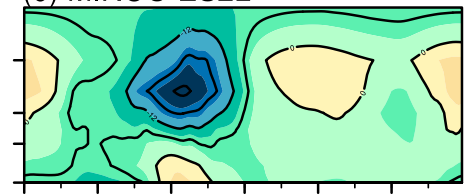

(r) NESM3

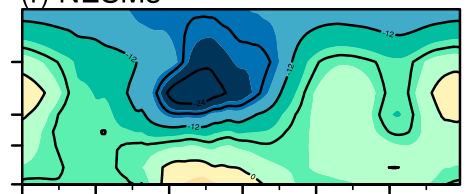

(u) 16MME minus Merged-OBS

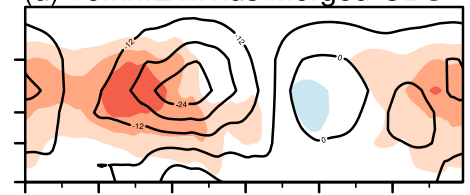

60W 0 \begin{tabular}{cccccc}
0 & $60 \mathrm{E}$ & $120 \mathrm{E}$ & 180 & $120 \mathrm{~W}$ \\
\hline & $\mid$ & $\mid$ & $\mid$ & $\mid$ & $\mid$ \\
\hline-6 & -4 & -2 & 2 & 4 & 6
\end{tabular}

FIG. 2. As in Fig. 1, but for the vertical section of zonal wind averaged along $0^{\circ}-15^{\circ} \mathrm{N}$ from 500 to $50 \mathrm{hPa}$. The contour interval is $6 \mathrm{~m} \mathrm{~s}^{-1}$, and only easterlies are plotted.

The overall performance of the 16 CMIP6 models is illustrated in Figs. $3 \mathrm{a}$ and $3 \mathrm{~b}$ by evaluating the pattern correlation coefficient (PCC) and normalized rootmean-square error (NRMSE) against the merged observation in the upper-level zonal wind over tropics $\left(10^{\circ} \mathrm{S}-25^{\circ} \mathrm{N}\right.$; Fig. 1$)$ and vertical section averaged along $0^{\circ}-15^{\circ} \mathrm{N}$ (Fig. 2). The NRMSE is calculated as the RMSE normalized by the spatial standard deviation of the merged observation. For tropical upper-level zonal wind, the models' PCCs range from 0.83 to 0.96 and the NRMSE from 0.39 to 0.91 (Fig. 3a). A relatively large range in PCC (0.77-0.96) and NRMSE (0.35-1.0) can be found for the vertical section of the zonal wind (Fig. 3b). Models with higher PCC tend to show smaller NRMSE 
(a) Tropical U200 (10S-25N)

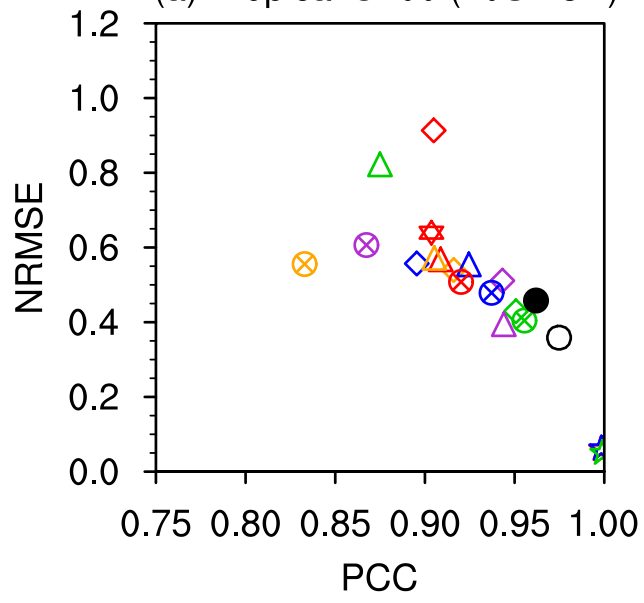

(c) Western TEJ

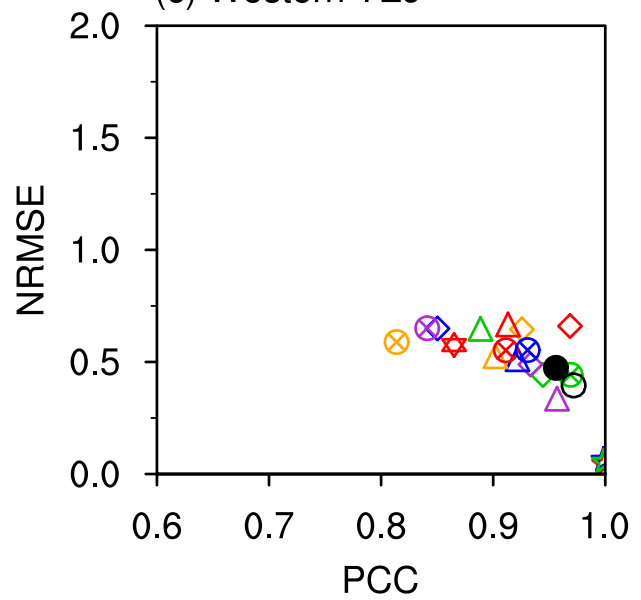

(b) Vertical U $(0-15 \mathrm{~N})$

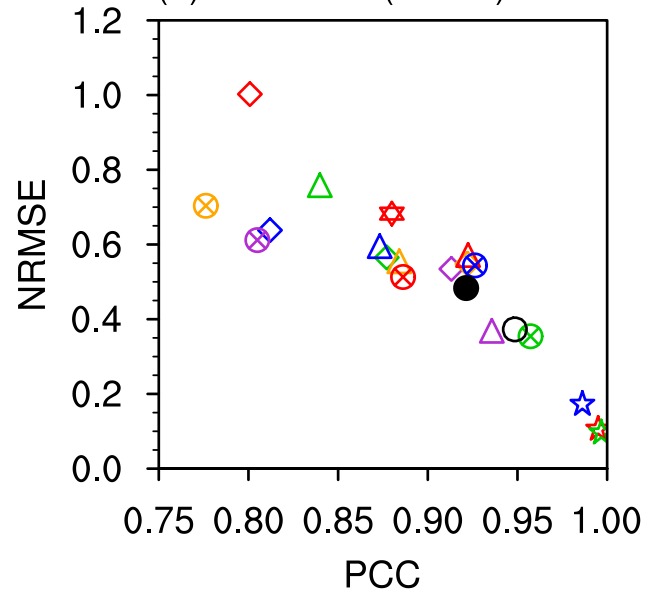

(d) Eastern TEJ

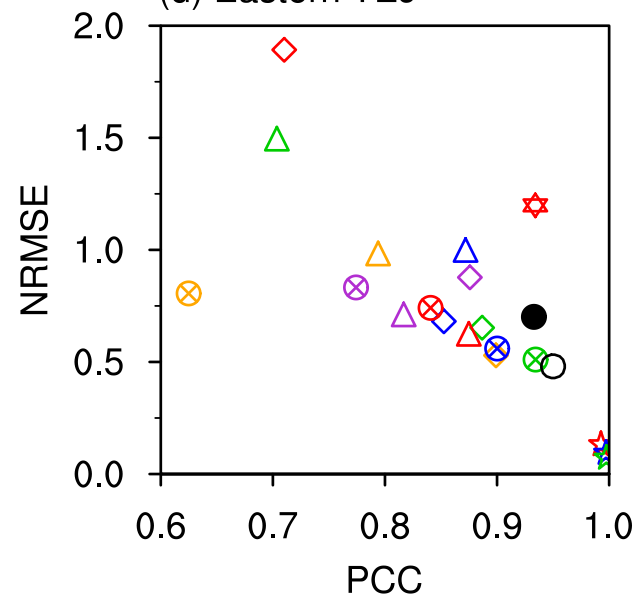

OB5MME

$\triangle$ CNRM-CM6-1

$\triangle$ GFDL-ESM4

\begin{tabular}{|c|c|c|c|c|}
\hline 话ERAI & 㑱CEP2 & 㑱JRA55 & 16MME & OB5MME \\
\hline$\diamond$ BCC-CSM2-MR & $\diamond$ CanESM5 & $\diamond$ CESM2-WACCM & $\diamond \mathrm{CESM} 2$ & $\diamond \mathrm{CNRM}-\mathrm{CM} 6-1$ \\
\hline$\triangle$ CNRM-ESM2-1 & $\triangle E C$-Earth3-Veg & $\triangle \mathrm{FGOALS-g3}$ & $\triangle$ GFDL-CM4 & $\triangle$ GFDL-ESM4 \\
\hline$\otimes I P S L-C M 6 A-L R$ & $\otimes M I R O C-E S 2 L$ & $\otimes$ MIROC6 & $\otimes M R I-E S M 2-0$ & QNESM3 \\
\hline
\end{tabular}

UKESM1-0-LL

FIG. 3. Performance of each observation, 16 individual models, and the $16 \mathrm{MME}$ verified against the merged observations on (a) 200-hPa zonal wind $\left(10^{\circ} \mathrm{S}-25^{\circ} \mathrm{N}, 0^{\circ}-360^{\circ}\right)$, (b) vertical structure of zonal wind averaged along $0^{\circ}-$ $15^{\circ} \mathrm{N}$, (c) western TEJ $\left(10^{\circ} \mathrm{S}-25^{\circ} \mathrm{N}, 60^{\circ}-160^{\circ} \mathrm{W}\right.$; large blue box in Fig. 1a), and (d) eastern TEJ $\left(5^{\circ} \mathrm{S}-20^{\circ} \mathrm{N}, 160^{\circ}-\right.$ $60^{\circ} \mathrm{W}$; small blue box in Fig. 1a) in boreal summer during 1995-2014. The abscissa and ordinate are PCC and spatially averaged RMSE normalized by the merged observed spatial standard deviation, respectively. The reference data are the merged observations. B5MME denotes the MME of the best five models with the best representation of the TEJ climatology used in future projection (see section 4), which are CESM2-WACCM, GFDL-CM4, IPSLCM6A-LR, MIROC-ES2L, and MIROC6.

both in Figs. $3 a$ and $3 b$. To assess the TEJ more accurately, the TEJ is divided into two parts. The western jet represents the jet extending from Atlantic eastward to the central Pacific $\left(10^{\circ} \mathrm{S}-25^{\circ} \mathrm{N}, 60^{\circ}-160^{\circ} \mathrm{W}\right.$; large blue box in Fig. 1a) and the eastern jet denotes the jet mainly confined to central-eastern Pacific and northern South America $\left(5^{\circ} \mathrm{S}-20^{\circ} \mathrm{N}, 160^{\circ}-60^{\circ} \mathrm{W}\right.$; small blue box in Fig. $\left.1 \mathrm{a}\right)$. The models can reproduce the observed western jet realistically (Fig. 3c), but they show poorer skills in capturing the eastern jet (Fig. 3d). The PCC ranges from 
(a) Mean Easterly wind $I_{\text {mean }}$

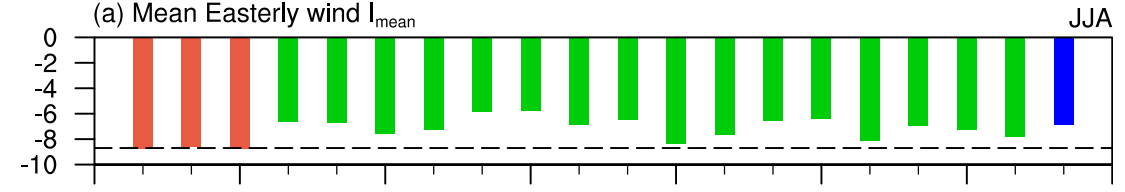

(b) Extension $I_{\text {extent }}$

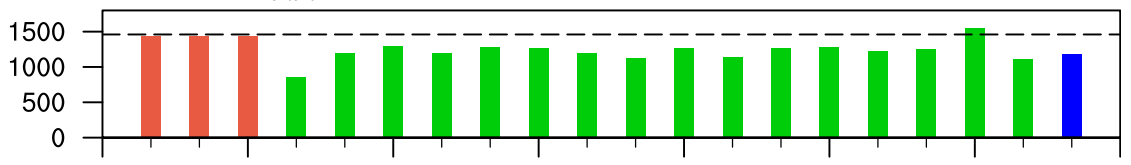

(c) Jet center over $10 \mathrm{I}_{10}$
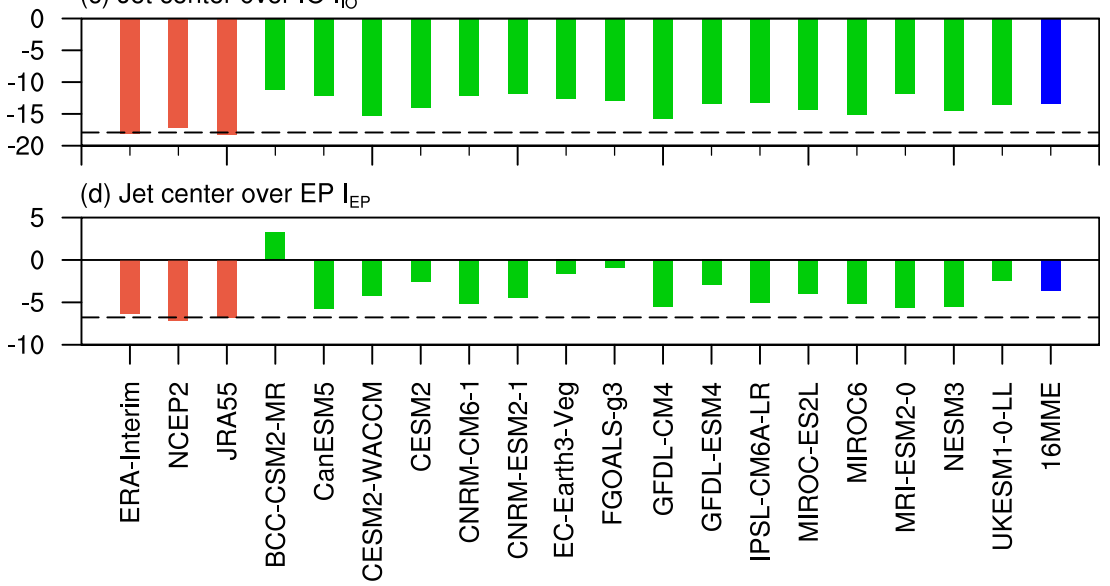

FIG. 4. Overall assessment of each observation (red), 16 individual models (green), and the $16 \mathrm{MME}$ (blue) verified against the merged observation on (a) the TEJ's mean intensity $I_{\text {mean }}$, (b) extent $I_{\text {extent }}$, and (c) intensity in the TEJ's center over the IO $\left(I_{\mathrm{IO}} ; 5^{\circ} \mathrm{S}-20^{\circ} \mathrm{N}, 40^{\circ}-100^{\circ} \mathrm{E}\right.$; large red box in Fig. 1a) and (d) over the EP $\left(I_{\mathrm{EP}} ; 0^{\circ}-15^{\circ} \mathrm{N}, 130^{\circ}-80^{\circ} \mathrm{W}\right.$; small red box in Fig. 1a) in boreal summer during 1995-2014.

0.81 to 0.97 and NRMSE from 0.34 to 0.66 for the western jet (Fig. 3c), and the PCC from 0.62 to 0.93 and NRMSE from 0.51 to 1.89 for the eastern jet (Fig. 3d). Note that the $16 \mathrm{MME}$ does not show the best performance in the above aspects of the TEJ, but MIROC6 (X mark in green circle) outperforms the 16MME in either PCC or NRMSE (Figs. 3a-d).

Figure 4 compares the TEJ index derived from observations and model simulations. It is found that all 16 CMIP6 models exhibit smaller values in $I_{\text {mean }}, I_{\mathrm{IO}}$, and $I_{\mathrm{EP}}$ compared to observations, suggesting an underestimation in the intensity of the jet with respect to the averaged TEJ, jet centers over IO and EP. Specifically, GFDL-CM4 and MIROC6 simulate the strongest $I_{\text {mean }}$ and $I_{\mathrm{IO}}$, while CNRM-CM6.1 and CNRM-ESM2.1 produce the weakest $I_{\text {mean }}$ and $I_{\mathrm{IO}}$. BCC-CSM2-LR even simulates westerly over the EP where easterly prevails in observation. The intensity of the observed easterly is $-8.1,-17.9$, and $-6.8 \mathrm{~m} \mathrm{~s}^{-1}$ for $I_{\text {mean }}, I_{\mathrm{IO}}$, and $I_{\mathrm{EP}}$, respectively, and the $16 \mathrm{MME}$ underestimates them by $22 \%, 25 \%$, and $47 \%$, respectively. As for the extent of TEJ, most of the CMIP6 models produce a smaller size of TEJ with an averaged reduction of about $19 \%$, except for NESM3, which exaggerates the TEJ's extent (Fig. 4b).

\section{b. Seasonal evolution and interannual variability}

As a prominent component of the monsoon system, the TEJ manifests distinct seasonal evolution associated with the onset and withdrawal of monsoon (Ding et al. 1988). The weakest $I_{\text {mean }}$ associated with a smaller $I_{\text {extent }}$ is observed in boreal spring (Figs. 5a,b). As the Northern Hemisphere monsoon develops, the easterly strengthens and expands from May, reaching a maximum in August. Then the $I_{\text {mean }}$ and $I_{\text {extent }}$ decrease gradually by November and increase slightly during boreal winter. The 16MME does reasonably well in capturing the observed seasonal cycle of the intensity and extent of the TEJ. However, it underestimates the intensity throughout the year and the extent from late spring to fall.

The seasonal migration of the central location of the jet core can be found in the IO TEJ (Fig. 5c). Both the merged observation and 16MME show that the jet center locates near the equator in a weak amplitude 
(a) Mean easterly wind $I_{\text {mean }}$

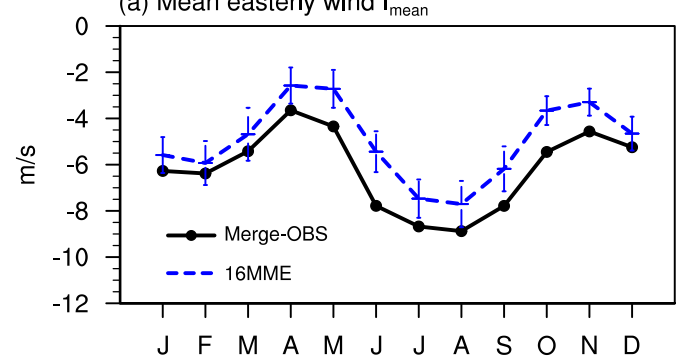

(c) IO TEJ $I_{\text {lon }}$ and $I_{\text {lat }}$

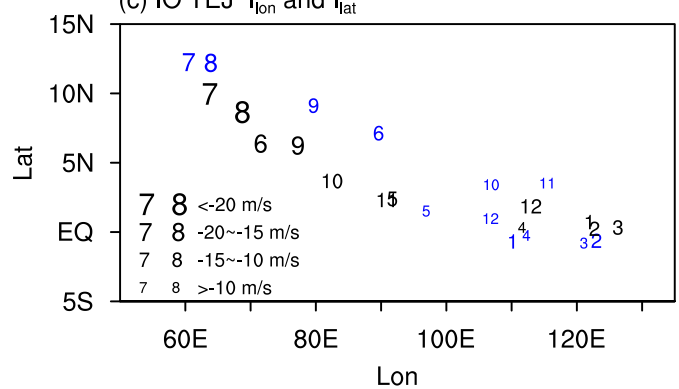

(b) Extent $I_{\text {exten }}$

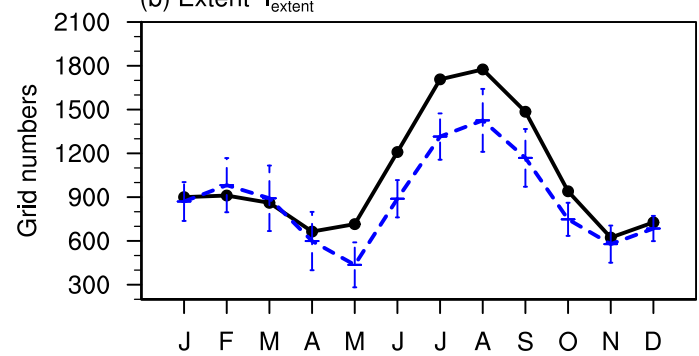

(d) EP TEJ $I_{\text {Ion }}$ and $I_{\text {lat }}$

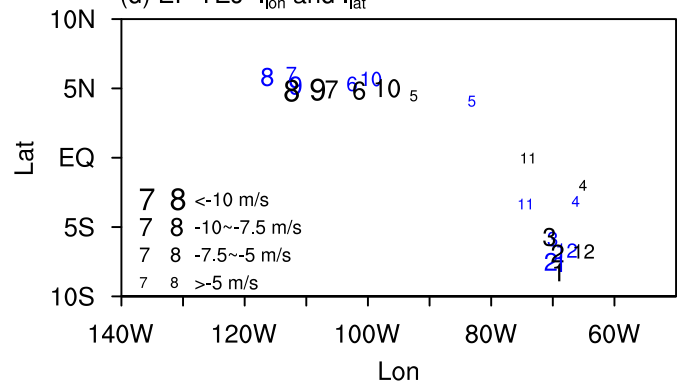

FIG. 5. Seasonal evolution of (a) the TEJ's mean intensity $I_{\text {mean }}$, (b) extent $I_{\text {extent }}$, and (c) the longitude (abscissa) and latitude (ordinate) of the TEJ's center over the IO and (d) over the EP for the merged observations (black) and 16MME (blue), respectively. The model spreads (vertical bars) in (a) and (b) are calculated as the standard deviation of 16 models. The numbers in (c) and (d) denote the corresponding months, and the sizes represent the intensity of the jet center.

from December to April, then moves northwestward and intensifies gradually after the onset of the Asian summer monsoon. It reaches the most northwestern position in July and August with a maximum wind speed higher than $20 \mathrm{~ms}^{-1}$, followed by a southeastward movement and weakening associated with the retreat of the monsoon. The 16MME exhibits a northward bias (about $2^{\circ}-3^{\circ}$ ) from June to September. In contrast, the EP TEJ shows little seasonal migration, but two distinct and separated modes (Fig. 5d). The TEJ dominates over EP in Northern Hemisphere associated with the North America summer monsoon from May to October while the TEJ locates over northern South America from November to the following April. The 16MME reproduces the two modes of the EP TEJ realistically with a slight northward and westward displacement from June to October.

Interannual variability also features the TEJ, whose leading mode can be identified using the empirical orthogonal function (EOF). In observation, the leading mode of the TEJ, which explains about $37.6 \%$ of the total variance, represents consistently negative anomalies in two jet centers and a positive anomaly in the entrance region over the western and central Pacific (Fig. 6a). It indicates a coherent variation in the intensity of two jet centers, which is mainly modulated by El Niño-Southern Oscillation (ENSO) (Arkin 1982;
Tanaka 1982; Chen and van Loon 1987). The cooling over the central-eastern Pacific favors suppressed rainfall in situ and enhanced rainfall over the Maritime Continent via intensifying the Walker circulation (Figs. 6c,e). The suppressed rainfall over tropical Pacific triggers upperlevel easterly anomalies to its east from the tropical EP eastward to tropical IO as Kelvin wave responses via the release of latent heat, which is in accordance with the result of Huang et al. (2019). Meanwhile, the enhanced rainfall over the Maritime Continent associated with the divergent center at the upper level favors easterly anomalies over the IO. The 16MME exhibits a high reproducibility in the spatial distribution of the leading mode of TEJ as well as its association with ENSO and rainfall (Figs. 6b,d,f). Still, an underestimation of the variability occurs among most CMIP6 models, which is supported by the weaker amplitude of the anomalies and a smaller explained variance $(30.4 \%)$. Besides, the overestimation of cooling in the tropical western IO and the underestimation of warming in the tropical eastern Atlantic are also identified (Fig. 6d).

\section{Future change of the TEJ under SSP585}

Considering the significant spread among individual models, efforts have been made to optimally select some best models in representing the TEJ in the historical 

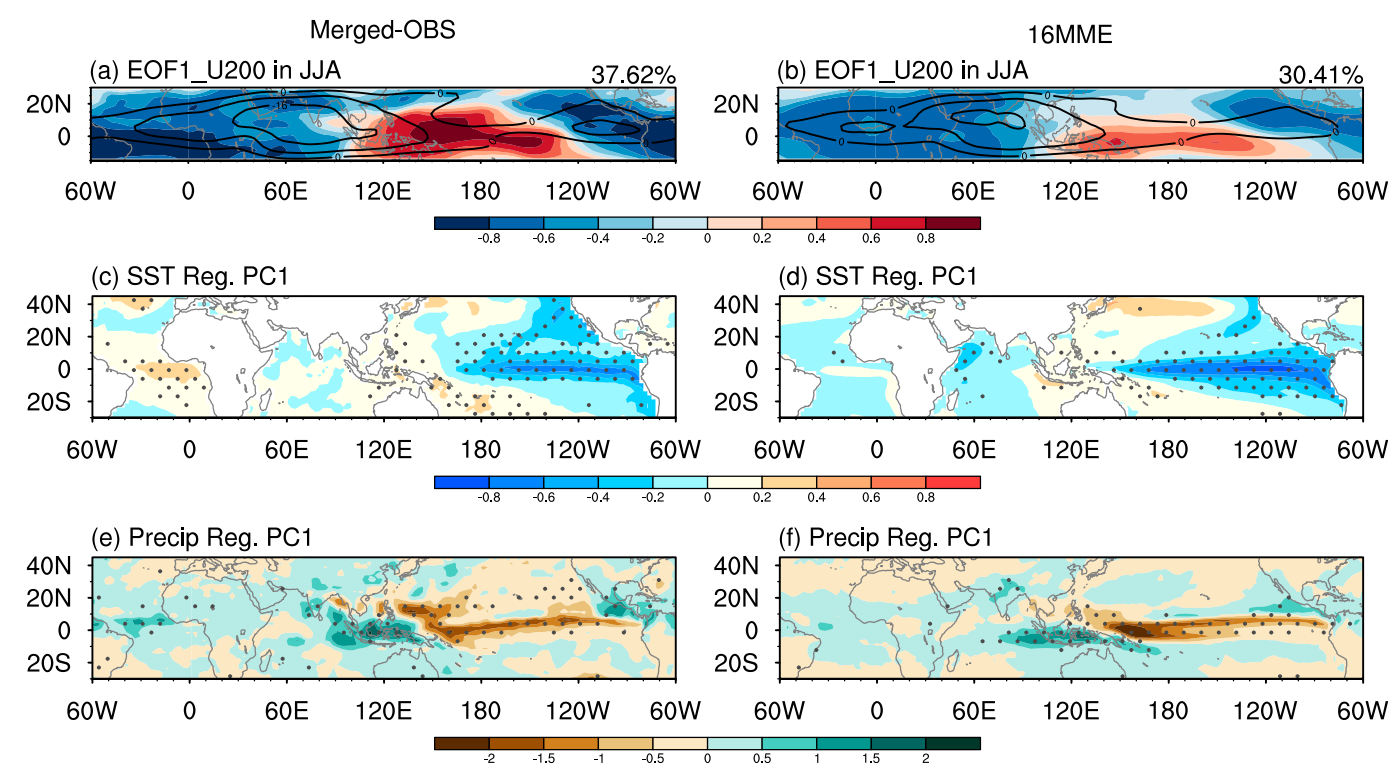

FIG. 6. (a),(b) The spatial distribution of the leading mode of $200-\mathrm{hPa}$ zonal wind (shading; $\mathrm{m} \mathrm{s}^{-1}$ ) in boreal summer from 1995-2014. (c),(d) SST (shading; ${ }^{\circ} \mathrm{C}$ ) and (e),(f) precipitation (shading; $\mathrm{mm} \mathrm{day}^{-1}$ ) regressed against the principal component of the TEJ's leading mode (i.e., PC1) for (left) the merged observations and (right) 16MME. The contours with an interval of $8 \mathrm{~m} \mathrm{~s}^{-1}$ in (a) and (b) denote the climatological easterly wind for the merged observation and 16MME, respectively. The dots in (d) and (f) denote significant at $90 \%$ confidence level in at least half of models.

period for the sake of more faithful future projection. The model selection is based on the ranking of NRMSE for the horizontal and vertical distribution of the tropical zonal wind, the western and eastern jet (Fig. 3). Only the model with the NRMSE ranking higher than half of the 16 models for all four aspects is selected. There are five models selected as the "best" models in simulating the TEJ, which are CESM2-WACCM, GFDL-CM4, IPSL-CM6A-LR, MIROC-ES2L, and MIROC6. The MME of the best five models (B5MME) exhibits better skills than 16MME in depicting the TEJ's climatology in boreal summer (Fig. 3) as well as the TEJ's variability (figure not shown). Besides, the B5MME also shows high reproducibility in the present-day tropical precipitation and SST pattern (figure not shown), which further provides more evidence to use the B5MME to project the TEJ changes. Therefore, the B5MME is used to examine the future change of the TEJ by comparing the difference between present-day simulation (1995-2014) and SSP585 scenario (2081-2100) in this section.

\section{a. Mean state change in boreal summer}

Figures $7 \mathrm{a}$ and $7 \mathrm{~b}$ illustrate the projected change in the TEJ under the SSP585 scenario. The B5MME projects an apparent weakening in the two jet centers and a reduction of the jet's extent over the northern EP (Figs. 7a,b). The intensity of the IO TEJ tends to weaken in amplitude by $2.7 \mathrm{~m} \mathrm{~s}^{-1}$ (about $18 \%$ ). Meanwhile, the projected EP TEJ decreases dramatically by $3.7 \mathrm{~m} \mathrm{~s}^{-1}$ (about $77 \%$ ), indicating the disappearance of the jet center over EP in future climate. Correspondingly, the projected mean easterly wind and extent decrease by about $11 \%$ and $6 \%$, respectively, implying a general weakening of the tropical upper-level circulation.

The underlying mechanisms for the maximum reduction occurring over the IO and EP are also examined. Corresponding to the reduced easterlies in the two jet centers, relatively low pressure and cold center are projected to the north of the jet centers at the upper level (Fig. 7c), indicating negative meridional pressure gradient anomaly and meridional temperature gradient (MTG) anomaly over the IO and EP. Projected enhanced rainfall dominates over the equatorial western Pacific, associated with the suppressed rainfall over tropical eastern IO in amplitude of $1.5 \mathrm{~mm} \mathrm{day}^{-1}$ (about $25 \%$ ) (Fig. 7e) via the connection of anomalous Walker circulation. The suppressed rainfall over tropical eastern IO maintains the upper-level convergence and leads to the anomalous divergent westerly (Fig. 7d). The rainfallinduced divergent westerly only explains $18 \%$ of the total westerlies, suggesting a handful of the contribution of the suppressed rainfall over tropical eastern IO to the weakening of the IO TEJ. The projected tropical precipitation pattern also indicates a southward shift in the 


\section{Changes projected by B5MME}
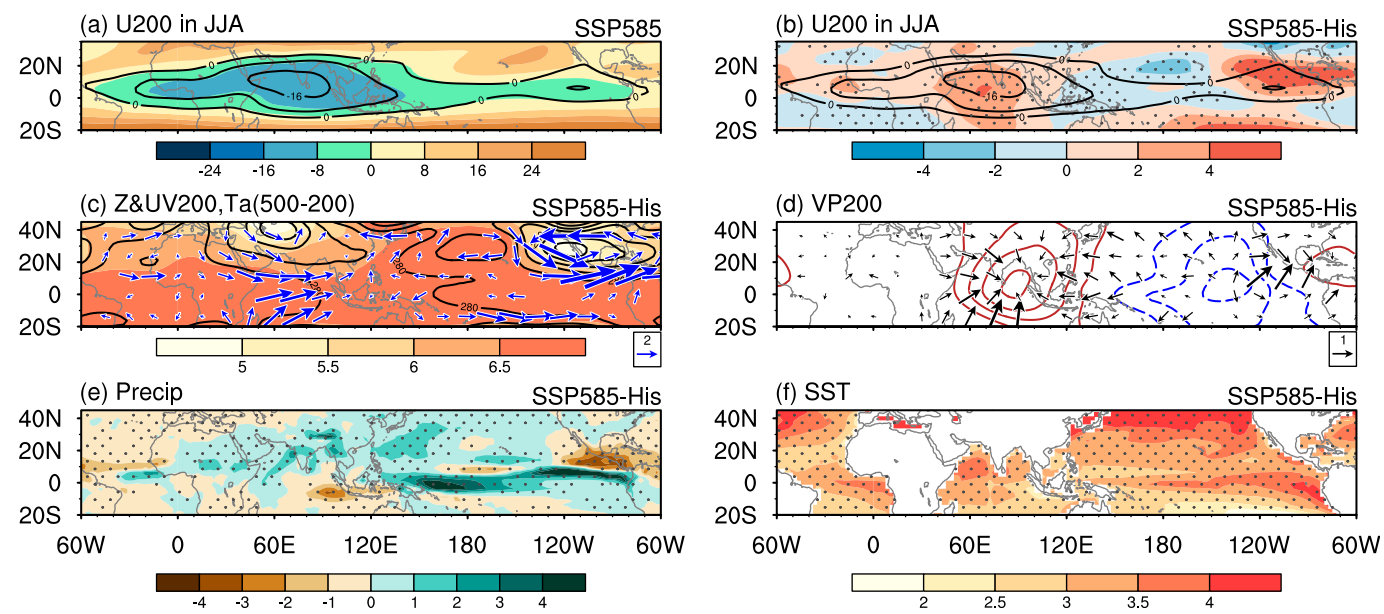

FIG. 7. (a) Climatological zonal wind at $200 \mathrm{hPa}$ during 2081-2100 (shading; $\mathrm{m} \mathrm{s}^{-1}$ ) using the B5MME. Projected changes in (b) 200-hPa zonal wind (shading; $\mathrm{m} \mathrm{s}^{-1}$ ), (c) 200-hPa geopotential height (contour; gpm), horizontal winds (vectors; $\mathrm{m} \mathrm{s}^{-1}$ ) and 500-200-hPa averaged temperature (shading; K), (d) 200-hPa velocity potential (contour; $10^{6} \mathrm{~s}^{-1}$ ) and divergent wind (vectors; $\mathrm{m} \mathrm{s}^{-1}$ ), (e) precipitation (shading; mm day ${ }^{-1}$ ), and (f) SST (shading; ${ }^{\circ} \mathrm{C}$ ) between the SSP585 simulation (2081-2100) and historical simulation (1995-2014) using the B5MME. The contours in (a) and (b) denote the climatological easterly wind in the historical period. The contour intervals in (a)-(d) are $8 \mathrm{~m} \mathrm{~s}^{-1}, 8 \mathrm{~m} \mathrm{~s}^{-1}, 10 \mathrm{gpm}$, and $1 \times 10^{6} \mathrm{~s}^{-1}$, respectively. The vectors in (c) and (d) and dots in (e) and (f) indicate where all of the best five models have the same sign.

intertropical convergence zone and precipitation over Central America tends to decrease by $2.9 \mathrm{~mm} \mathrm{day}^{-1}$ (about $36 \%$ ). The noticeably suppressed rainfall over Central America excites a strong cyclonic circulation to its north at the upper level as Rossby wave responses, resulting in anomalous westerlies along the southern flank of the cyclone and thus weakening the EP TEJ (Fig. 7c). The above precipitation anomalies can be attributed to an El Niño-like warming over the tropical Pacific via the "warmerget-wetter" mechanism (Fig. 7f), which is consistent with previous studies (e.g., Meehl and Washington 1996; Chadwick et al. 2014; Huang et al. 2013; Ma and Xie 2013).

Distinct changes can also be found in the vertical structure of the TEJ (Figs. 8a,b). The projected IO TEJ exhibits a significant upward lift, consistent with the change in the MTG according to the thermal wind balance. The MTG is negative (warmer in the south) between 500 and $200 \mathrm{hPa}$ but positive (warmer in the north) between 150 and $100 \mathrm{hPa}$ (Fig. 8c). The uneven distribution in the vertical temperature might be associated with uneven upward heat transport linked to the model cumulus parameterization schemes and/or cloudradiation feedback. As for the EP TEJ, reduced easterlies extend from 300 to $100 \mathrm{hPa}$, coherent with the local negative MTG (Figs. 8b,d).

\section{b. Seasonal evolution and interannual variability}

Figure 9 presents the projected seasonal evolution of the TEJ, which suggests that the seasonal cycle of the TEJ will not change appreciably by the end of the twenty-first century. Specifically, a slight weakening in the easterly wind is projected from November to July by about $0.6 \mathrm{~m} \mathrm{~s}^{-1}$, accompanied by a slight reduction in the TEJ's extent (Figs. 9a,b). Little change can be seen in the location of the IO TEJ except for a slight eastward shift in May, June, September, and October (Fig. 9c). The projected EP TEJ exhibits a significant southeastward displacement from July to October, which is coherent with the reduction of extent over the northern EP (Fig. 9d).

The projected TEJ's interannual variability and its association with the tropical SST and precipitation are shown in Fig. 10. The projected leading mode is similar to that in the historical period whose explained variance was $36 \%$ but in a smaller amplitude and explained variance $(34.4 \%)$ (Figs. 10a,b). The TEJ's relationship with ENSO remains similar in future climate (Figs. 10c,d), as the correlation coefficient between the principal component of the TEJ's leading mode (i.e., PC1) and Niño-3 index $\left(5^{\circ} \mathrm{S}-5^{\circ} \mathrm{N}, 150^{\circ}-90^{\circ} \mathrm{W}\right)$ shows a trivial change ( -0.83 in the present day and -0.84 in the future). Note that the related SST anomalies over the central Pacific 


\section{Changes projected by B5MME}

(a) $\mathrm{U}(0-15 \mathrm{~N})$ in JJA

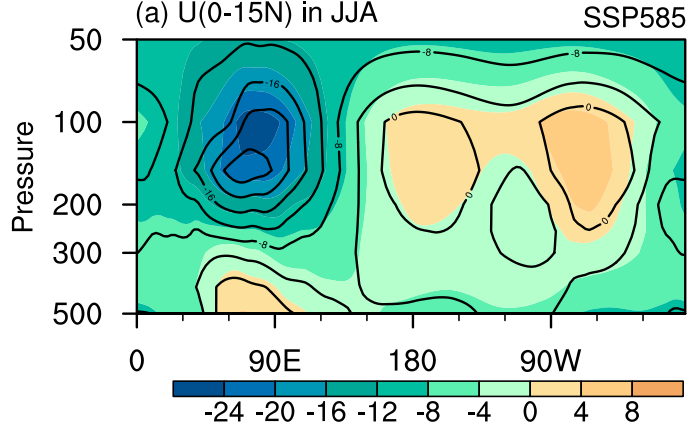

(c) T (40-100E) SSP585-His

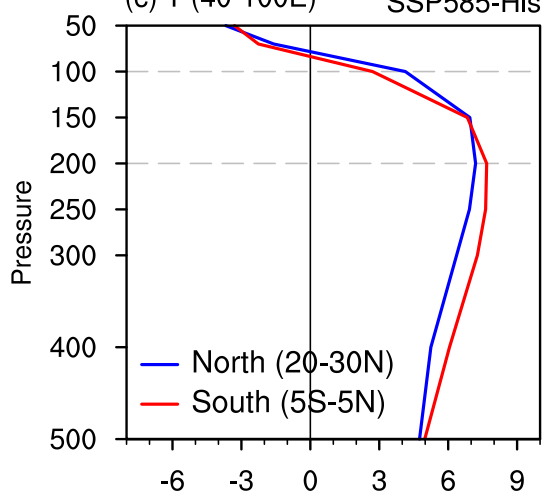

(b) U_Diff

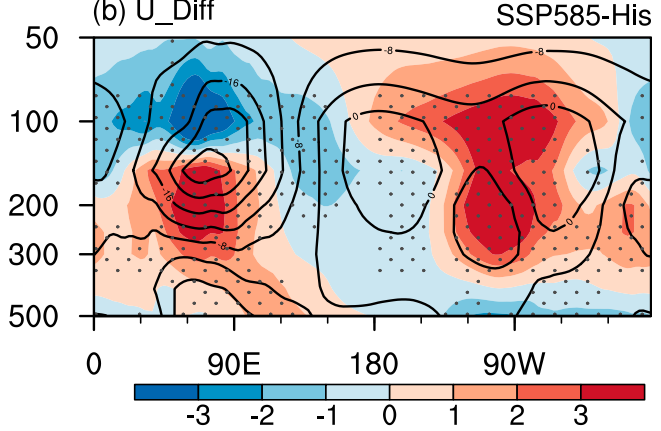

(d) T (130W-80W) SSP585-His

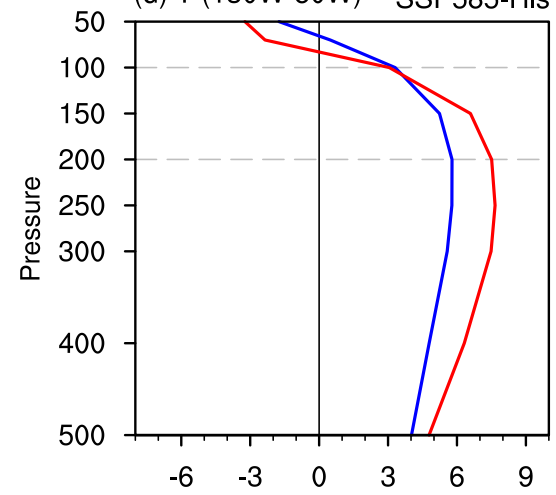

FIG. 8. (a) Climatological zonal wind at $200 \mathrm{hPa}$ averaged along $0^{\circ}-15^{\circ} \mathrm{N}$ (shading; $\mathrm{m} \mathrm{s}^{-1}$ ) and (b) the projected changes (shading; $\mathrm{m} \mathrm{s}^{-1}$ ) during 2081-2100 using the B5MME. The contours with an interval of $4 \mathrm{~m} \mathrm{~s}^{-1}$ in (a) and (b) denote the climatological easterly wind in historical period. Difference in temperature change $\left({ }^{\circ} \mathrm{C}\right)$ over the northern region $\left(20^{\circ}-30^{\circ} \mathrm{N}\right)$ and the southern region $\left(5^{\circ} \mathrm{S}-5^{\circ} \mathrm{N}\right)$ averaged along (c) the IO region $\left(40^{\circ}-100^{\circ} \mathrm{E}\right)$ and (d) the EP region $\left(130^{\circ}-80^{\circ} \mathrm{W}\right)$. The dots in (b) indicate where all of the best five models have the same sign.

exhibit a slight eastward shift, which is likely linked to a deepening of the thermocline in tropical Pacific response to global warming, and so does in the related precipitation pattern (Figs. 10e,f). Accordingly, a zonal narrowness and a meridional expansion of the maximum positive anomalies of the leading mode is projected (Fig. 10b).

\section{c. Model uncertainty}

Although CMIP aims to assess the future climate change under global warming, the uncertainty remains an obstacle for a faithful projection. Figure 11 presents the intermodel uncertainty of the projected changes in TEJ using 16 CMIP6 models. All models have an agreement on the weakening of the centers of the TEJ, projecting a range of $0.7-7.7 \mathrm{~m} \mathrm{~s}^{-1}$ for the IO TEJ and $0.7-8.0 \mathrm{~m} \mathrm{~s}^{-1}$ for the EP TEJ. In contrast, the models show inconsistency in the signs of changes with respect to the mean easterly wind $\left(I_{\text {mean }}\right)$ and extent $\left(I_{\text {extent }}\right)$, implying a considerable model uncertainty in the TEJ projection. Such a large uncertainty is discernable not only among 16 models but also among the best five models. Despite the B5MME projects a weakened $I_{\text {mean }}$, IPSL-CM6A-LR exhibits a slight strengthening. CESMWACCM projects the largest magnitude in the weakening of the centers of the IO and EP TEJs, implying a more sensitive response of atmospheric circulation to global warming. GFDL-CM4 simulates an expansion of the TEJ in future climate against the other four models.

An interesting question remains as to what causes the model uncertainty of the TEJ projection. Since the observed interannual variability TEJ is primarily controlled by ENSO (Fig. 6) and the uncertainties in the projected tropical Pacific SST changes can influence the projections of atmospheric circulations ( $\mathrm{Ma}$ and Xie 2013; Long et al. 2016), it is hypothesized that the projected tropical Pacific SST changes play a critical role in the model uncertainties of the TEJ projection. Hence, the relationship between the changes of the IO TEJ and EP TEJ and the changes of the projected tropical 
(a) Mean easterly wind $I_{\text {mean }}$

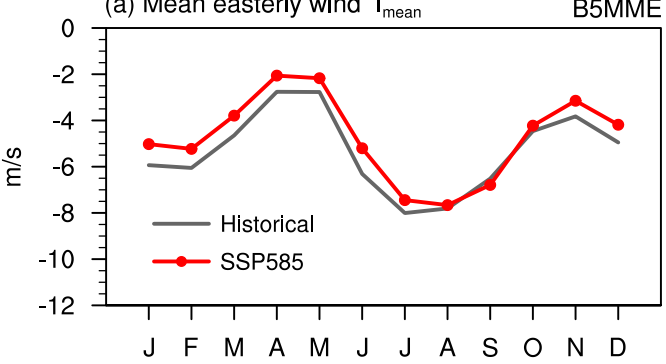

(c) IO TEJ $I_{\text {lon }}$ and $I_{\text {lat }}$

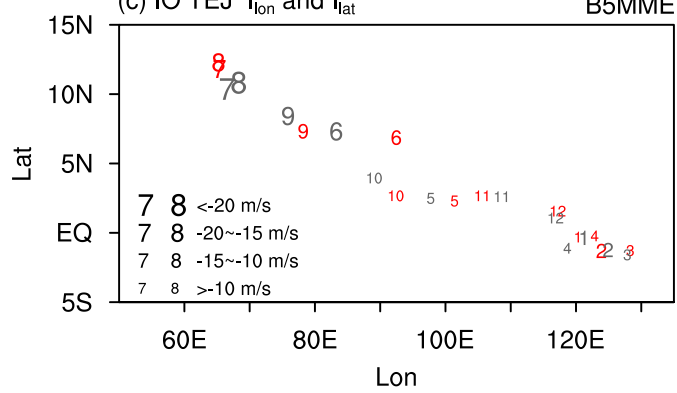

(b) Extent $I_{\text {extent }}$

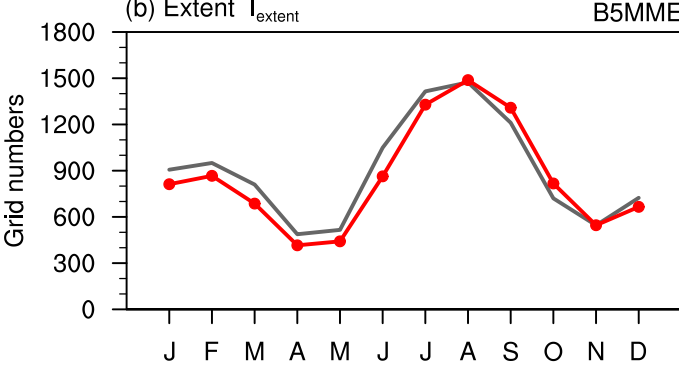

(d) EP TEJ I Ion and $I_{\text {lat }}$

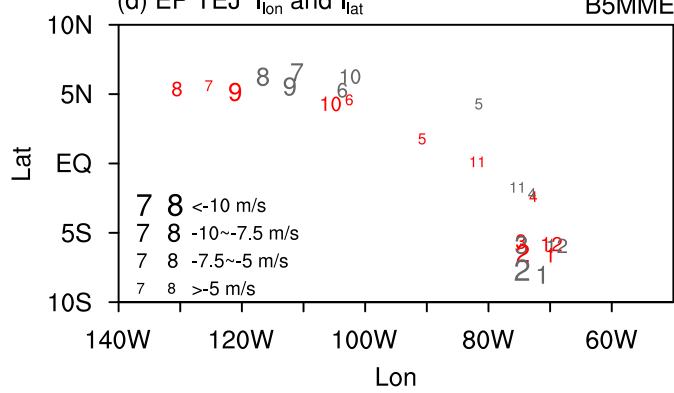

FIG. 9. Seasonal evolution of (a) the TEJ's mean intensity $I_{\text {mean }}$, (b) extension $I_{\text {extent }}$, and (c) the longitude (abscissa) and latitude (ordinate) of the TEJ's center over the IO and (d) over the EP using the B5MME for historical simulation (gray) and SSP585 simulation (red), respectively. The numbers in (c) and (d) denote the corresponding months, and the sizes represent the intensity of the jet center.

eastern Pacific SST among 16 individual models is examined (Fig. 12). Results show that the changes of both the IO TEJ and EP TEJ are indeed significantly correlated with the projected Niño-3 SST changes with the correlation coefficient of $0.62(P<0.05)$ and $0.76(P<$ $0.01)$, respectively. This suggests that the models that project the tropical eastern Pacific warming pattern predict weaker TEJs in both the IO and EP. The
Historical in B5MME

(a) EOF1_U200 in JJA

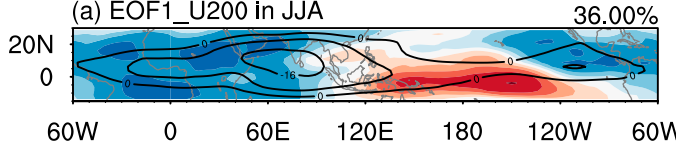

SSP585 in B5MME

(b) EOF1_U200 in JJA

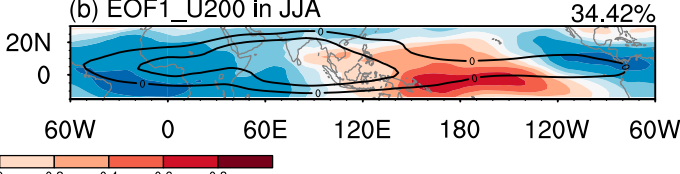

(c) PC1 Reg. SST
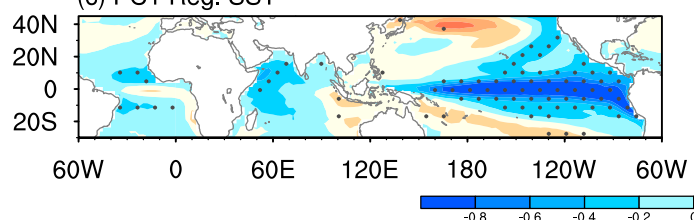

(e) PC1 Reg. Precip

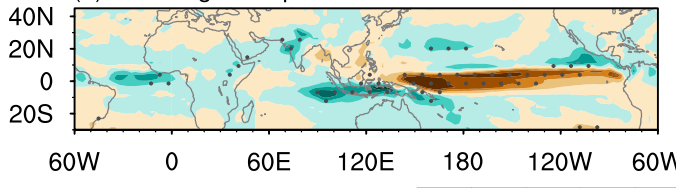

(d) PC1 Reg. SST

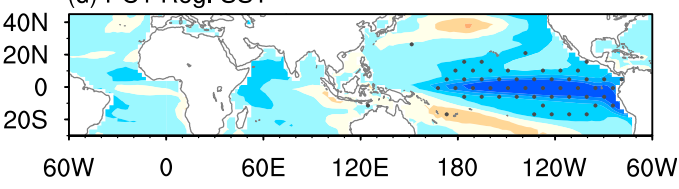

(f) PC1 Reg. Precip

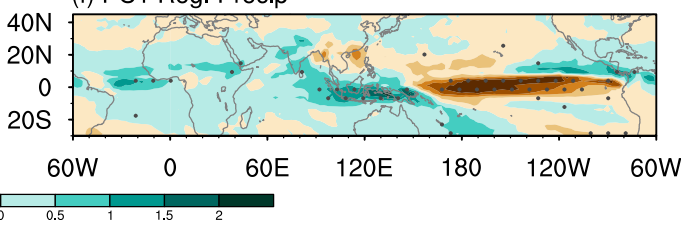

FIG. 10. (a),(b) Spatial distribution of the leading mode of 200-hPa zonal wind (shading; $\mathrm{m} \mathrm{s}^{-1}$ ) in boreal summer during 2081-2100 using the B5MME. (c),(d) SST (shading; ${ }^{\circ} \mathrm{C}$ ) and (e),(f) precipitation (shading; $\mathrm{mm} \mathrm{day}^{-1}$ ) regressed against PC1 for (left) the historical simulation and (right) the SSP585 simulation. The contours with an interval of $8 \mathrm{~m} \mathrm{~s}^{-1}$ in (a) and (b) denote the climatological easterly wind in the historical simulation and SSP585 simulation, respectively. The dots in (c)-(f) denote significant at $90 \%$ confidence level in at least half of the best five models. 


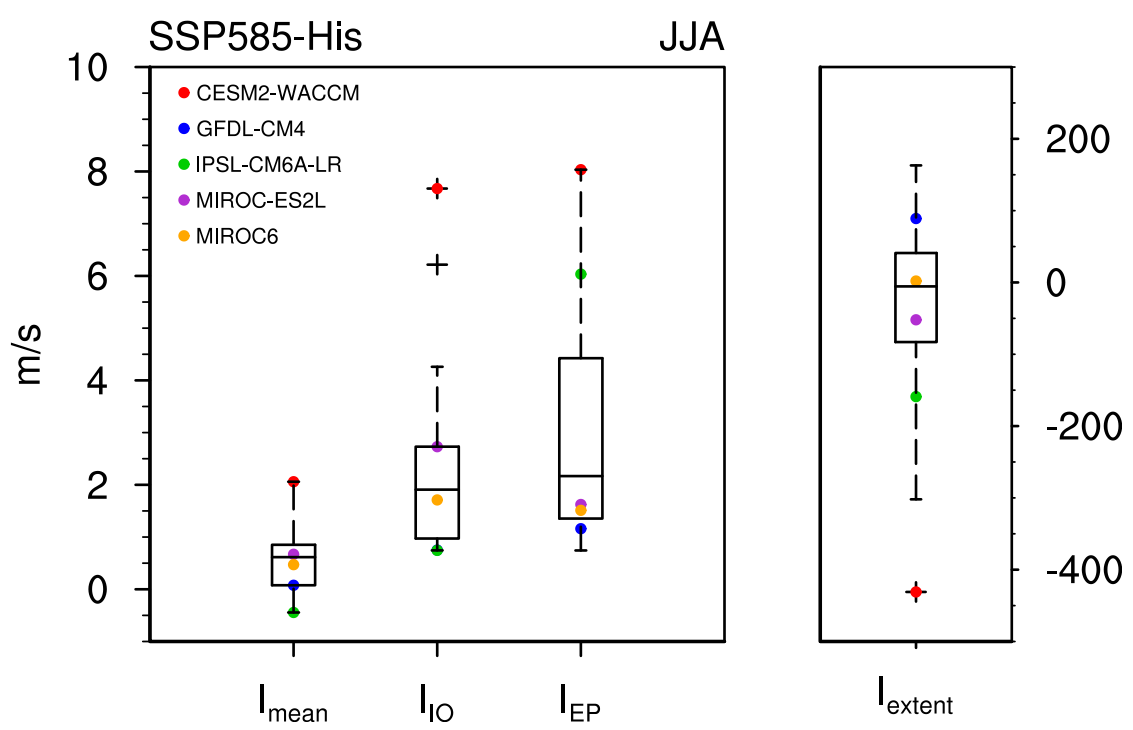

FIG. 11. Box plots of projected changes in four TEJ indices (i.e., $I_{\text {mean }}, I_{\mathrm{IO}}, I_{\mathrm{EP}}$, and $I_{\text {extent }}$ ) in boreal summer of 16 CMIP6 models. The box represents the interquartile range (IQR) and contains $50 \%$ of the data. The upper edge of the box represents the 75th percentile $\left(Q_{u}\right)$ and the lower edge is the 25 th percentile $\left(Q_{l}\right)$. The horizontal line within the box is the median. The vertical dashed line represents the range of the nonoutliers. Crosses represent outliers that are either greater than $Q_{u}+1.5 \times \mathrm{IQR}$ or less than $Q_{l}-1.5 \times \mathrm{IQR}$. The dots represent the best five models with better skills in simulating the TEJ climatology.

mechanism behind this relationship is consistent with that by which ENSO affects the TEJ. The model spread also indicates that the future changes of the TEJ are likely to be dependent on the projected Niño-3 SST changes.

\section{d. Sensitivity of the projected changes to the model selection}

The future projections are usually provided by all models ensemble mean (e.g., Wang et al. 2020) or some selected models that can best simulate the climate systems' climatology and/or variability in the historical simulation (e.g., Lee and Wang 2014). We should note that any selected group of models cannot warrant a reliable projection. However, we can test the sensitivity of the projections to the selection method to examine how different the projections will be. Different from the best five models based on the TEJ climatology mentioned above, an alternative selection metric is based on the
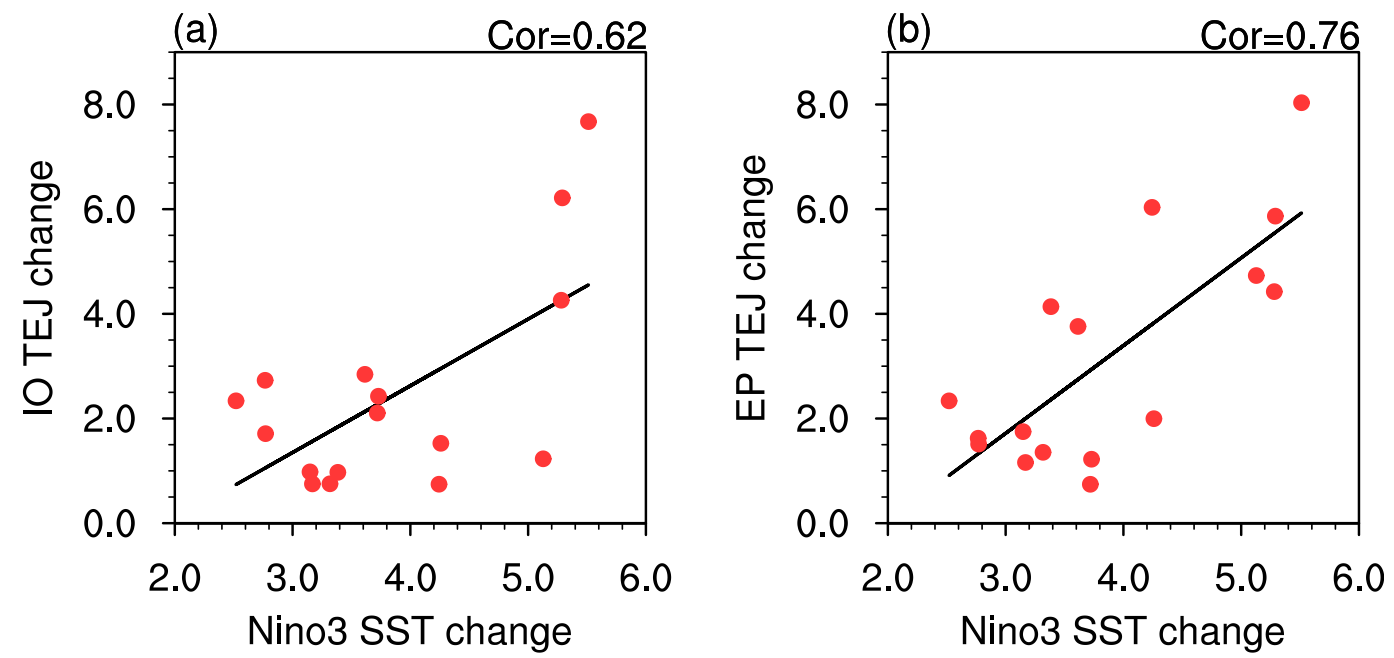

FIG. 12. Relationship between the Niño-3 SST changes (abscissa; $5^{\circ} \mathrm{S}-5^{\circ} \mathrm{N}, 150^{\circ}-90^{\circ} \mathrm{W}$ ) and the changes of the intensity of (a) the IO TEJ $\left(I_{\mathrm{IO}}\right)$ and (b) the EP TEJ $\left(I_{\mathrm{EP}}\right)$. The intermodel correlation coefficient is shown at the top-right side in each panel. 


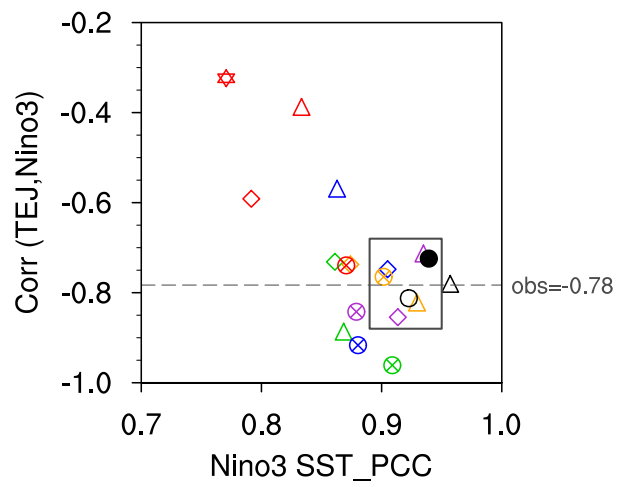

$\begin{array}{lllll}\bullet 16 M M E & \triangle \text { B5MME-SST } & \text { OB5MME } & & \\ \diamond \text { BCC-CSM2-MR } & \diamond \text { CanESM5 } & \diamond \text { CESM2-WACCM } & \diamond \text { CESM2 } & \diamond \text { CNRM-CM6- } \\ \triangle \text { CNRM-ESM2-1 } & \triangle \text { EC-Earth3-Veg } & \triangle \text { FGOALS-g3 } & \triangle \text { GFDL-CM4 } & \triangle \text { GFDL-ESM4 } \\ \otimes I P S L-C M 6 A-L R & \otimes \text { MIROC-ES2L } & \otimes \text { MIROC6 } & \otimes \text { MRI-ESM2-0 } & \otimes N E S M 3\end{array}$

QUKESM1-0-L

FIG. 13. Performance of the 16 individual models, the $16 \mathrm{MME}$ (black dot), the B5MME-SST (black triangle), and the B5MME (black circle) against the observation on the Niño 3 SST pattern and the Niño-3 SST-TEJ relationship. The abscissa denotes the PCC of the regressed tropical Pacific SST pattern $\left(120^{\circ} \mathrm{E}-80^{\circ} \mathrm{W}\right.$, $20^{\circ} \mathrm{S}-20^{\circ} \mathrm{N}$ ) onto the Niño-3 index in 16 individual models against the observation. The ordinate denotes the correlation coefficient between the Niño-3 index and the PC1 of the TEJ's leading mode. The B5MME-SST denotes the MME of the five selected models (i.e., CanESM5, CESM2, GFDL-CM4, GFDL-ESM4, and NESM3; colorful markers in black box). The dashed line indicates the observed correlation coefficient between the Niño-3 index and $\mathrm{PC} 1$.

models' skills in the simulated Niño-3 SST anomaly and the relationship between the Niño-3 SST and the TEJ. This new criterion considers the dominant role of the ENSO in the observed TEJ variability as well as the role of projected Niño-3 SST changes in the future changes of the TEJ. Using this new criterion, five new models, CanESM2, CESM2, GFDL-CM4, GFDLESM4, and NESM3, are selected (Fig. 13). These five models largely differ from the best five models based on the TEJ climatology, with only one model, GFDL-CM4, in common.

Figure 14 compares the projections of the IO and EP TEJ using the MME of the best five models based on the TEJ climatology (B5MME), the newly selected models based on simulated Niño-3 SST anomaly and its relationship with the TEJ (B5MME-SST), and all 16 models (16MME). For the IO TEJ, the three projections are nearly the same before 2075. After 2075, the B5MME and B5MME-SST projections diverge, but their means are very close to the 16MME. For the EP TEJ, the B5MME-SST and 16MME project similar changes while the B5MME, projecting the weakening of the EP TEJ, is systematically stronger than the other two. Table 2 compares the climatological means and model spreads

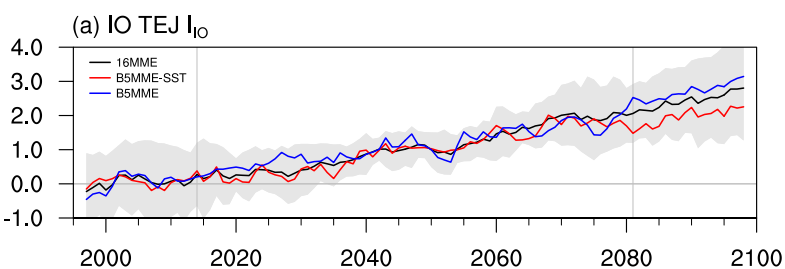

(b) EP TEJ $I_{E P}$

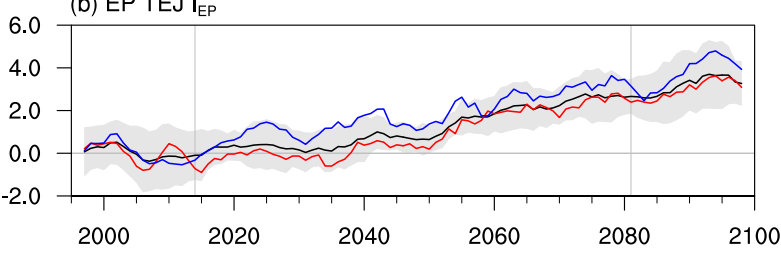

FIG. 14. Changes in (a) the IO TEJ $\left(I_{\mathrm{IO}}\right)$ and $(\mathrm{b})$ the EP TEJ $\left(I_{\mathrm{EP}}\right)$ using the 16MME (black), B5MME-SST (red), and B5MME (blue). The shading denotes the model spread of 16MME, which is defined as one standard deviation of the individual model's departure from the MME. The anomaly is obtained from the climatology of 1995-2014. A 5-yr moving average is applied to all time series. The vertical lines denote the years of 2014 and 2081, respectively.

(i.e., intermodel standard deviation) during 2081-2100 for the projected IO and EP TEJ changes among three projections. It is demonstrated that the three projections share highly consistent projections of the IO TEJ and EP TEJ with very similar climatological means and standard deviations. Furthermore, the Student's $t$ test and $F$ test are used to evaluate the statistical significance of the means and standard deviations among three projections, respectively. Results show that the differences in means and standard deviations among the three projections for both the IO and EP TEJs are hardly statistically significant at a $90 \%$ confidence level. This suggests that the different model selections do not yield significantly different results of the projected TEJ changes.

\section{Summary and discussion}

The CMIP provides the opportunity for a better understanding of the past, present, and future climate. Our motivation is to assess the model fidelity in representing the TEJ's climatology and variability and projecting future change under the SSP585 scenario by utilizing the latest CMIP6 models output.

Most of the CMIP6 models have the ability to represent the TEJ in terms of climatology, seasonal evolution, and interannual variability. However, models underestimate the intensity and extent of the TEJ, especially over the IO and EP TEJs. Such a bias can also be found in the seasonal evolution and the amplitude of interannual variation. 
TABLE 2. Climatological mean and intermodel standard deviation during 2081-2100 for the projected IO TEJ and EP TEJ changes using B5MME, B5MME-SST, and 16MME.

\begin{tabular}{|c|c|c|c|c|}
\hline & \multicolumn{2}{|c|}{ IO TEJ } & \multicolumn{2}{|c|}{ EP TEJ } \\
\hline & Mean $\left(\mathrm{m} \mathrm{s}^{-1}\right)$ & Standard deviation $\left(\mathrm{m} \mathrm{s}^{-1}\right)$ & $\operatorname{Mean}\left(\mathrm{m} \mathrm{s}^{-1}\right)$ & Standard deviation $\left(\mathrm{m} \mathrm{s}^{-1}\right)$ \\
\hline B5MME & 2.7 & 2.9 & 3.7 & 3.2 \\
\hline B5MME-SST & 2.0 & 2.0 & 3.0 & 2.2 \\
\hline $16 \mathrm{MME}$ & 2.4 & 2.4 & 3.2 & 2.2 \\
\hline
\end{tabular}

The multimodel ensemble projects a weakened TEJ by the end of the twenty-first century under the SSP585 scenario. Specifically, remarkable reductions occur in the central TEJ intensity over the IO (by about $18 \%$ ) and over the EP (by about $77 \%$ ). The dramatic reduction in the EP TEJ implies a disappearance of a jet core over the EP. Besides, the IO TEJ will be lifted upward due to the change in the vertical distribution of meridional temperature gradient. The mean intensity and extent of the TEJ will reduce by about $11 \%$ and $6 \%$, respectively, suggesting a significant weakening of the tropical upper-level circulation in the future climate. However, the TEJ's seasonal evolution and interannual variability remain roughly the same despite a slight decrease in the intensity and extent.

The dramatic weakening of the IO and EP TEJs is directly linked to the decrease of rainfall. The suppressed rainfall over tropical eastern IO might explain $18 \%$ of the weakening of the IO TEJ through generating the upper-level convergence and favoring divergent westerly over tropical IO. Other factors that contribute to the remaining $82 \%$ of the weakening still need to be unraveled. Suppressed rainfall over Central America with a decrease of about $36 \%$ may largely cause the weakening of EP TEJ. The reduced easterly corresponds to the upper-level cyclone over North America excited by the suppressed rainfall over Central America as Rossby wave responses. The projected tropical rainfall is likely attributed to the El Niño-like warming via the "warmer-get-wetter" mechanism under global warming.

Large model uncertainties remain in the projection of the TEJ, which may arise from the uncertainties of the projected tropical eastern Pacific SST changes. A projected warmer Niño-3 SST pattern corresponds to weaker TEJs in both the IO and EP. This is consistent with the observation that ENSO can affect TEJ variability. The results of different selection methods are compared to examine the sensitivity of the projection to the model selection. The B5MME-SST based on the simulated Niño-3 SST anomaly and its relationship with the TEJ and the 16MME project similar changes of the IO TEJ and EP TEJ as the B5MME does. This suggests that the selection of models does not result in significantly different future projections.

Our results show a westerly bias of the TEJ in 16MME and a significant intermodel diversity of the TEJ (Figs. 1 and 2). The intermodel diversity of the TEJ may arise from the models' simulated SST. The regression analysis on the historical simulations among 16 models indicates that the simulated cold SST over the South IO favors low-level northward cross-equatorial over the western IO which enhances the South Asian rainfall along the foothill of the Himalayas and the Bay of Bengal, thus contributing to a stronger IO TEJ (figure not shown). The simulated cooling over the Pacific cold tongue also enhances the low-level northward cross-equatorial flow and rainfall over the eastern North Pacific, which leads to a stronger EP TEJ (figure not shown). It is indicated that improving the simulated SST errors helps models produce a correct TEJ.

Figure 7 shows that the subsidence and anomalous heat sink are located over the equatorial IO, but the Rossby wave responses occur only in the Northern Hemisphere, leading to an asymmetric structure that differs from the symmetric response in the MatsunoGill model (Gill 1980; Matsuno 1966). This asymmetric response is mainly attributed to the presence of the monsoon easterly vertical shear in the Northern Hemisphere Asian monsoon region. Wang and Xie (1996) and Xie and Wang (1996) extended Matsuno's theory by including mean flows and demonstrated that an easterly vertical shear can drastically amplify moist Rossby waves while westerly shears tend to reduce them. The related mechanisms by which the vertical shear can change the Rossby wave responses are discussed in detail in their papers. Such an asymmetric response was also illustrated by a linearized general circulation model experiment (Figs. 5 and 6 in Wang et al. 2003), indicating a crucial role of the vertically sheared flow in modulating the Rossby wave response.

The SSP585 scenario is chosen in the present manuscript since it is the highest emission scenario to investigate the maximum change in the TEJ that can be expected. However, it does not imply that this scenario is the most likely condition in the future. The dramatic 
weakening of the TEJ under the SSP585 scenario raises the implication that the changes of the TEJ may be held under other lower emission scenarios. Further research on the comparison of the TEJ projection under different pathways is imperative to detect the sensitivity of the TEJ changes to global warming.

Acknowledgments. The authors thank the three anonymous reviewers for their constructive comments to significantly improve the manuscript. We acknowledge the World Climate Research Programme's Working Group on Coupled Modeling, which is responsible for the CMIP. We thank the Earth System Grid Federation for data dissemination and climate modeling groups listed in Table 1 of this paper. This research is jointly supported by National Key Research and Development Program of China (2016YFA0600601) and National Natural Science Foundation of China (41530530, 41875087). B.W. acknowledges the support of NSF/Climate Dynamics Award AGS-1540783. This is the International Pacific Research Center (IPRC) Publication No. 1454, School of Ocean and Earth Science and Technology (SOEST) Publication No. 11093, and Earth System Modeling Center (ESMC) Publication No. 314.

\section{REFERENCES}

Adler, R. F., and Coauthors, 2003: The version-2 Global Precipitation Climatology Project (GPCP) monthly precipitation analysis (1979-present). J. Hydrometeor., 4, 1147-1167, https:// doi.org/10.1175/1525-7541(2003)004<1147:TVGPCP $>2.0$.CO;2.

Arkin, P. A., 1982: The relationship between interannual variability in the $200 \mathrm{mb}$ tropical wind field and the Southern Oscillation. Mon. Wea. Rev., 110, 1393-1404, https://doi.org/ 10.1175/1520-0493(1982)110<1393:TRBIVI>2.0.CO;2.

Balaji, V., and Coauthors, 2018: Requirements for a global data infrastructure in support of CMIP6. Geosci. Model Dev., 11, 3659-3680, https://doi.org/10.5194/gmd-11-3659-2018.

Barlow, M., S. Nigam, and E. H. Berbery, 1998: Evolution of the North American monsoon system. J. Climate, 11, 2238-2257, https:// doi.org/10.1175/1520-0442(1998)011<2238:EOTNAM >2.0.CO;2.

Chadwick, R., P. Good, T. Andrews, and G. Martin, 2014: Surface warming patterns drive tropical rainfall pattern responses to $\mathrm{CO}_{2}$ forcing on all timescales. Geophys. Res. Lett., 41, 610-615, https://doi.org/10.1002/2013GL058504.

Chen, T., and H. van Loon, 1987: Interannual variation of the tropical easterly jet. Mon. Wea. Rev., 115, 1739-1759, https://doi.org/ 10.1175/1520-0493(1987)115<1739:IVOTTE>2.0.CO;2.

Ding, Y., S. Zhao, and X. Fu, 1988: A study of the long-term mean circulation at $200 \mathrm{hPa}$ over the global tropics and subtropics during northern summer-Part II: Planetary-scale wind systems (in Chinese). Chin. J. Atmos. Sci., 12, 242-249, https:// doi.org/10.3878/j.issn.1006-9895.1988.03.03.

Douglas, M. W., R. A. Maddox, K. Howard, and S. Reyes, 1993: The Mexican monsoon. J. Climate, 6, 1665-1677, https:// doi.org/10.1175/1520-0442(1993)006<1665:TMM >2.0.CO;2.

Eyring, V., S. Bony, G. A. Meehl, C. A. Senior, B. Stevens, R. J. Stouffer, and K. E. Taylor, 2016: Overview of the Coupled
Model Intercomparison Project Phase 6 (CMIP6) experimental design and organization. Geosci. Model Dev., 9, 19371958, https://doi.org/10.5194/gmd-9-1937-2016.

Gill, A. E., 1980: Some simple solutions for heat-induced tropical circulation. Quart. J. Roy. Meteor. Soc., 106, 447-462, https:// doi.org/10.1002/qj.49710644905.

Haarsma, R. J., and F. Selten, 2012: Anthropogenic changes in the Walker circulation and their impact on the extra-tropical planetary wave structure in the Northern Hemisphere. Climate Dyn., 39, 1781-1799, https://doi.org/10.1007/s00382-012-1308-1.

He, C., and T. Zhou, 2014: The two interannual variability modes of the Western North Pacific Subtropical High simulated by 28 CMIP5-AMIP models. Climate Dyn., 43, 2455-2469, https:// doi.org/10.1007/s00382-014-2068-x.

Held, I. M., and B. J. Soden, 2006: Robust responses of the hydrological cycle to global warming. J. Climate, 19, 5686-5699, https://doi.org/10.1175/JCLI3990.1.

Higgins, R. W., Y. Yao, and X. L. Wang, 1997: Influence of the North American monsoon system on the U.S. summer precipitation regime. J. Climate, 10, 2600-2622, https://doi.org/ 10.1175/1520-0442(1997)010<2600:IOTNAM > 2.0.CO;2.

Huang, P., S.-P. Xie, K. Hu, G. Huang, and R. Huang, 2013: Patterns of the seasonal response of tropical rainfall to global warming. Nat. Geosci., 6, 357-361, https://doi.org/10.1038/ngeo1792.

Huang, S., Z. Wen, Z. Chen, X. Li, R. Chen, and Y. Guo, 2019: Interdecadal change in the relationship between the tropical easterly jet and tropical sea surface temperature anomalies in boreal summer. Climate Dyn., 53, 2119-2131, https://doi.org/ 10.1007/s00382-019-04801-5.

Hulme, M., and N. Tosdevin, 1989: The tropical easterly jet and Sudan rainfall: A review. Theor. Appl. Climatol., 39, 179-187, https://doi.org/10.1007/BF00867945.

Kanamitsu, M., T. N. Krishnamurti, and C. Depradine, 1972: On scale interactions in the tropics during northern summer. J. Atmos. Sci., 29, 698-706, https://doi.org/10.1175/1520-0469(1972)029<0698: OSIITT $>2.0 . \mathrm{CO} ; 2$.

— W. Wbisuzaki, J. Woollen, S.-K. Yang, J. J. Hnilo, M. Fiorino, and G. L. Potter, 2002: NCEP-DOE AMIP-II Reanalysis (R-2). Bull. Amer. Meteor. Soc., 83, 1631-1644, https://doi.org/ 10.1175/BAMS-83-11-1631.

Kobayashi, S., and Coauthors, 2015: The JRA-55 reanalysis: General specifications and basic characteristics. J. Meteor. Soc. Japan, 93, 5-48, https://doi.org/10.2151/jmsj.2015-001.

Koteswaram, P., 1958: The easterly jet stream in the tropics. Tellus, 10, 43-57, https://doi.org/10.3402/tellusa.v10i1.9220.

Krishnamurti, T. N., and H. N. Bhalme, 1976: Oscillations of a monsoon system. Part I. Observational aspects. J. Atmos. Sci., 33, 1937-1954, https://doi.org/10.1175/1520-0469(1976) 033<1937:OOAMSP $>2.0$. CO;2.

Kusunoki, S., and O. Arakawa, 2012: Change in the precipitation intensity of the East Asian summer monsoon projected by CMIP3 models. Climate Dyn., 38, 2055-2072, https://doi.org/ 10.1007/s00382-011-1234-7.

— , and - 2015: Are CMIP5 models better than CMIP3 models in simulating precipitation over East Asia? J. Climate, 28, 5601-5621, https://doi.org/10.1175/JCLI-D-14-00585.1.

Lee, J. Y., and B. Wang, 2014: Future change of global monsoon in the CMIP5. Climate Dyn., 42, 101-119, https://doi.org/10.1007/ s00382-012-1564-0.

Long, S. M., S. P. Xie, and W. Liu, 2016: Uncertainty in tropical rainfall projections: Atmospheric circulation effect and the ocean coupling. J. Climate, 29, 2671-2687, https://doi.org/ 10.1175/JCLI-D-15-0601.1. 
Ma, J., and S. P. Xie, 2013: Regional patterns of sea surface temperature change: A source of uncertainty in future projections of precipitation and atmospheric circulation. J. Climate, 26, 2482-2501, https://doi.org/10.1175/JCLI-D-12-00283.1.

Maloney, E. D., and Coauthors, 2014: North American climate in CMIP5 experiments: Part III: Assessment of twenty-firstcentury projections. J. Climate, 27, 2230-2270, https://doi.org/ 10.1175/JCLI-D-13-00273.1.

Matsuno, T., 1966: Quasi-geostrophic motions in the equatorial area. J. Meteor. Soc. Japan, 44, 25-43, https://doi.org/10.2151/ jmsj1965.44.1_25.

Meehl, G. A., and W. M. Washington, 1996: El Niño-like climate change in a model with increased atmospheric $\mathrm{CO}_{2}$ concentrations. Nature, 382, 56-60, https://doi.org/10.1038/382056a0.

Murakami, T., B. Wang, and S. W. Lyons, 1992: Contrasts between summer monsoons over the Bay of Bengal and the eastern North Pacific. J. Meteor. Soc. Japan, 70, 191-210, https:// doi.org/10.2151/jmsj1965.70.1B_191.

Ogata, T., and Coauthors, 2014: Projected future changes in the Asian monsoon: A comparison of CMIP3 and CMIP5 model results. J. Meteor. Soc. Japan, 92, 207-225, https://doi.org/ 10.2151/jmsj.2014-302.

O'Neill, B. C., and Coauthors, 2016: The Scenario Model Intercomparison Project (ScenarioMIP) for CMIP6. Geosci. Model Dev., 9, 3461-3482, https://doi.org/10.5194/gmd-93461-2016.

Pattanaik, D. R., and V. Satyan, 2000: Fluctuations of tropical easterly jet during contrasting monsoons over India: A GCM study. Meteor. Atmos. Phys., 75, 51-60, https://doi.org/10.1007/s007030070015.

Rao, B. R. S., D. V. B. Rao, and V. B. Rao, 2004: Decreasing trend in the strength of Tropical Easterly Jet during the Asian summer monsoon season and the number of tropical cyclonic systems over Bay of Bengal. Geophys. Res. Lett., 31, L14103, https://doi.org/10.1029/2004GL019817.

Rayner, N. A., D. E. Parker, E. B. Horton, C. K. Folland, L. V. Alexander, D. P. Rowell, E. C. Kent, and A. Kaplan, 2003: Global analyses of sea surface temperature, sea ice, and night marine air temperature since the late nineteenth century. J. Geophys. Res., 108, 4407, https://doi.org/10.1029/2002JD002670.

Riahi, K., and Coauthors, 2017: The shared socioeconomic pathways and their energy, land use, and greenhouse gas emissions implications: An overview. Global Environ. Change, 42, 153168, https://doi.org/10.1016/j.gloenvcha.2016.05.009.

Sathiyamoorthy, V., P. K. Pal, and P. C. Joshi, 2004: Influence of the upper-tropospheric wind shear upon cloud radiative forcing in the Asian monsoon region. J. Climate, 17, 2725-2735, https:// doi.org/10.1175/1520-0442(2004)017<2725:IOTUWS >2.0.CO;2.

Seo, K. H., J. Ok, J. H. Son, and D. H. Cha, 2013: Assessing future changes in the East Asian summer monsoon using CMIP5 coupled models. J. Climate, 26, 7662-7675, https://doi.org/ 10.1175/JCLI-D-12-00694.1.

Simmons, A., S. Uppala, D. Dee, and S. Kobayashi, 2007: ERAInterim: New ECMWF reanalysis products from 1989 onwards.
ECMWF Newsletter, No. 110, 25-35, https://www.ecmwf.int/ sites/default/files/elibrary/2007/17713-era-interim-new-ecmwfreanalysis-products-1989-onwards.pdf.

Song, F., and T. Zhou, 2014: Interannual variability of East Asian summer monsoon simulated by CMIP3 and CMIP5 AGCMs: Skill dependence on Indian Ocean-western Pacific anticyclone teleconnection. J. Climate, 27, 1679-1697, https://doi.org/10.1175/ JCLI-D-13-00248.1.

Sooraj, K. P., P. Terray, and P. Xavier, 2016: Sub-seasonal behaviour of Asian summer monsoon under a changing climate: Assessments using CMIP5 models. Climate Dyn., 46, 40034025, https://doi.org/10.1007/s00382-015-2817-5.

Sperber, K. R., H. Annamalai, I. S. Kang, A. Kitoh, A. Moise, A. Turner, B. Wang, and T. Zhou, 2013: The Asian summer monsoon: An intercomparison of CMIP5 vs. CMIP3 simulations of the late 20th century. Climate Dyn., 41, 2711-2744, https://doi.org/10.1007/s00382-012-1607-6.

Stouffer, R. J., V. Eyring, G. A. Meehl, S. Bony, C. Senior, B. Stevens, and K. E. Taylor, 2017: CMIP5 scientific gaps and recommendations for CMIP6. Bull. Amer. Meteor. Soc., 98, 95-105, https://doi.org/10.1175/BAMS-D-15-00013.1.

Tanaka, M., 1982: Interannual the fluctuations of the tropical easterly monsoon in the Asian region. J. Meteor. Soc. Japan, 60, 865-875, https://doi.org/10.2151/jmsj1965.60.3_865.

Ueda, H., A. Iwai, K. Kuwako, and M. E. Hori, 2006: Impact of anthropogenic forcing on the Asian summer monsoon as simulated by eight GCMs. Geophys. Res. Lett., 33, L06703, https://doi.org/10.1029/2005GL025336.

van Vuuren, D. P., and Coauthors, 2011: The representative concentration pathways: An overview. Climatic Change, 109, 531, https://doi.org/10.1007/s10584-011-0148-z.

Vecchi, G. A., and B. J. Soden, 2007: Global warming and the weakening of the tropical circulation. J. Climate, 20, 43164340, https://doi.org/10.1175/JCLI4258.1.

Wang, B., and X. Xie, 1996: Low-frequency equatorial waves in vertically sheared zonal flow. Part I: Stable waves. J. Atmos. Sci., 53, 449-467, https://doi.org/10.1175/1520-0469(1996)053<0449: LFEWIV $>2.0 . \mathrm{CO} ; 2$.

-, R. Wu, and T. Li, 2003: Atmosphere-warm ocean interaction and its impacts on Asian-Australian monsoon variation. J. Climate, 16, 1195-1211, https://doi.org/10.1175/ 1520-0442(2003)16<1195:AOIAII >2.0.CO;2.

, S. Y. Yim, J. Y. Lee, J. Liu, and K. J. Ha, 2014: Future change of Asian-Australian monsoon under RCP 4.5 anthropogenic warming scenario. Climate Dyn., 42, 83-100, https://doi.org/ 10.1007/s00382-013-1769-x.

— C. Jin, and J. Liu, 2020: Understanding future change of global monsoons projected by CMIP6 models. J. Climate, $\mathbf{3 3}$, 6471-6489, https://doi.org/10.1175/JCLI-D-19-0993.1.

Xie, X., and B. Wang, 1996: Low-frequency equatorial waves in vertically sheared zonal flow. Part II: Unstable waves. J. Atmos. Sci., 53, 3589-3605, https://doi.org/10.1175/1520-0469(1996)053<3589: LFEWIV>2.0.CO;2. 